Apidologie, 1973, 4 (3), 227-265.

\title{
ÜBER DEN EINFLUSS VON METAMORPHOSE- HÄUTUNGSSTÖRUNGEN UND LIGATUREN AUF DIE SPERMATOGENESE DER HONIGBIENE (APIS MELLIFICA L.)
}

Sur l'influence des perturbations de la métamorphose nymphale et des ligatures sur la spermatogénèse de l'abeille (Apis mellifica L).

W. FYG

Bubenbergstrasse 27

3700 Spiez (Schweiz)

\section{SUMMARY}

THE INFLUENCE OF METAMORPHIC DISTURBANCES OF ECDYSIS

AND OF LIGATURES ON THE SPERMATOGENESIS OF THE HONEYBEE (Apis mellifica L.)

Post cephalic and post thoracic disturbances of ecdysis, often occurring with male prepupae after elimination of the larval cocoon, frequently are causing an abnormal course of spermatogenesis. In the testes, giant spermatocytes and anomalous spermatids are found which only partly transform into sperm.

By original drawings the normal and the anomalous spermatogenesis are described. In the discussion the suppositionis expressed, saying that the anomalous spermatogenesis may depend on hormonal in fluences.

\section{ZUSAMMENF ASSUNG}

Postcephale und postthorakale Unterbindungen bei spinnenden Drohnenlarven und Metamorphose-Häutungsstörungen, wie sie bei Drohnenstreckmaden nach Elimination des Larvengespinstes häufig auftreten, haben vielfach einen regelwidrigen Verlauf der Spermatogenese zur Folge. In den Hoden treten Riesenspermatocyten und abnorme Spermatiden auf,

Hern Prof. Dr. F. Baltzer in Bern danke ich für die Durchsicht des Manuskriptes und seine Ratschläge recht herzlich. 
welche sich nur zum kleinsten Teil in Spermien verwandeln. An Hand von Originalzeichnungen wird zunächst die normale und dann die anormale Samenbildung beschrieben. In der anschliessenden Diskussion wird die Vermutung geäussert, dass die abnorme Spermatogenese der Honigbiene möglicherweise hormonbedingt sein könnte.

\section{EINLEITUNG}

Die Arbeiterinnen- und Drohnenmaden der Honigbiene stellen gegen das Ende der Larvenperiode die Nahrungsaufnahme ein und fertigen mit ihrem Spinndrüsensekret einen allseitig geschlossenen Kokon an, sobald ihre Wabenzellen von den Stockbienen verdeckelt worden sind. Die Entstehungsweise und der feinere Bau dieses Gespinstkokons wurden von v. ButtelReepen (1907), Arnhart (1919), Prell (1924), Velich (1930) und Jay (1963) genauer untersucht. Wenn die Larven ihren Kokon gesponnen und den Darm entleert haben, legen sie sich, den Kopf dem Zelldeckel zugewendet, ausgestreckt auf den Rücken und werden bewegungslos. Offenbar handelt es sich dabei um eine erregungs-symmetrische taktile Lageorientierung (Gontarski, 1957; Jay, 1961). Man bezeichnet diese Phase der postembryonalen Entwicklung als Streckmadenstadium. Sie dauert bei der Bienenarbeiterin durchschnittlich $2 \frac{1}{2}$, beim Drohn dagegen 4 Tage und findet ihren Abschluss mit der letzten Larven- oder sogenannten Metamorphosehäutung, wobei sich die Streckmade in die Puppe verwandelt. Nach Gontarski (1957) und J $J_{A Y}$ (1962) soll diese Häutung nur 15-35 Minuten beanspruchen.

Experimentelle Untersuchungen (Veurch, 1930; Fyg, 1956, 1956a, 1957, 1958, 1961) ergaben, dass die Metamorphosehäutung beim Fehlen des Larvengespinstes oder einer Unterlage von gleichwertiger Ober flächenbeschaffenheit oft ganz unterbleibt oder so regelwidrig verläuft, dass nur verkrüppelte und lebensunfähige Bienen entstehen. Das zeigt sich sehr schön, wenn man normale Arbeiterinnen- und Drohnenlarven unmittelbar nach der Beendigung des Spinnens als junge Streckmaden vorsichtig und unverletzt aus ihren Wabenzellen nimmt und sie ohne Kokon im Brutschrank bei einer Temperatur von $35{ }^{\circ} \mathrm{C}$ und einer relativen Luftfeuchtigkeit von $40-60 \%$ in flachen Glasschalen aufzieht. Bei allen Larven beginnt in den nächsten 24-36 Stunden die Abscheidung einer wasserklaren Häutungs flüssigkeit unter der sich allmählich abhebenden Exuvie. Parallel mit der bald einsetzenden Gliederung des Larvenkörpers erfolgt sie aber vielfach so reichlich, dass der Rumpf schon nach kurzer Zeit von einem abnorm grossen, transparenten Flüssigkeitssack umhüllt wird (Abb. 1). Das weitere Entwicklungsgeschehen ist bei den einzelnen Versuchstieren verschieden. Viele von ihnen vermögen sich ohne das Larvengespinst überhaupt nicht zu häuten und stellen ihre Weiterentwicklung ein. Nach einigen Tagen sind manche von diesen Maden schlaff und verfärbt, um schliesslich zugrunde zu gehen. Bei den restlichen Streckmaden beginnt die Metamorphosehäutung am Vorderende zunächst normal, kommt dann 
aber früher oder später plötzlich zum Stillstand. Die Exuvie, die noch den grössten Teil des sich verwandelnden Tieres umgibt, bleibt an den Antennen und den prognathen Mundgliedmassen hängen und wird nicht abgestreift. Die Kopf- und Thoraxanhänge werden dadurch in ihrer präpupalen Lage festgehalten und an der ordent lichen Streckung verhindert. Viele dieser Puppen entwickeln sich trotz der Häutungsstörung weiter und färben sich aus; es entstehen jedoch keine normalen, sondern nur mehr oder weniger verkrüppelte Bienen (Abb. 2), die nicht lebensfähig sind. Wie zahlreiche Experimente zeigten, reagieren die Drohnenstreckmaden merkwürdigerweise auf den Wegfall des Larvengespinstes weit weniger empfindlich als die entsprechenden

\section{ZEICHENERKLÄRUNGEN}

AвB. 1-15

A : Anus Ant : Antenne $B_{1^{-3}}$ : verkrüppelte Beine $C y s$ : Samenherde $E p$ : Epithel des Hodenschlauches $F_{a}:$ Komplexauge $F l$ : Flügel $F_{z}:$ Follikelzellen $G$, ep : germinales Epithel $K:$ Kern $L$ : Hämocyten $M g$ : mesodermales Hodengewebe $M g l$ : Mundgliedmassen $n$ : Mitochondrienknäuel (« Nebenkern ») $R$ : Polkörperchen Spc : Spermatocyten $S p c_{1}:$ Spermatocyten im Ruhestadium $S p c_{2}$ : Spermatocyten im vormeiotischen Stadium $S p c_{3}$ : Reifeteilungen $S p g:$ Spermatogonien $S_{p g_{1}}$ : sternförmig angeordnete Spermatogonien $S_{p g_{2}}$ : Spermatogonien-Mitosen $S p$ : Zwischenstufen der Spermiogenese $S_{p k}$ : Kerne der Spermien $S_{p m}$ : Spermien Spt : Spermatiden Tu : Peritonealhülle des Hodens.

ABB. 16-25

$E p$ : Epithel des Hodenschlauches $F z$ : Follikelzellen $S p c_{1}$ : normale Spermatocyten $S p c_{2}:$ heranwachsende Spermatocyten und Riesenspermatocyten Spm : Spermien $S p t:$ Spermatiden $S_{p t_{2}}$ : scheinbar einkernige Spermatiden $S p t_{2}:$ zweikernige Spermatiden.

AвB. 26 UND 27

Ao: Aorta $B a:$ Beinanlagen $C . a:$ Corpus allatum C.c: Corpus cardiacum $C g l:$ Oberschlundganglion (Gehirn) $F$ : Fettkörpergewebe $\dot{F}_{g l}$ : Frontalganglion $H y:$ Hypocerbralganglion $M:$ Mund $M d$ : Mitteldarm Mep : Mitteldarmepithel $N_{p}$ : Nervus procurrens $N r$ : Nervus recurrens $N_{z}:$ neurosekretorische Zellen Oes : Oesophagus $P d r$ : Prothorakaldrüsen $S p d:$ Spinndrüsen Sgl : Unterschlundganglion $T$ : Corpotentorium $T h g_{1}, T h g_{2}$ : erstes und zweites Thorakalganglion $T r$ : erste Brusttrachee $Z d:$ Zwischendarm.

\section{ABRÉVIATIONS}

Fig. 1 A 15

$A$ : anus Ant: antenne $B_{1_{-3}}:$ patte malformée $C y s$ : cyste $E p$ : épithélium du tube séminifère $F a$ : œil composé $F l:$ aile $F z:$ cellules folliculaires G.ep : épithélium germinal $K:$ noyau $L:$ hémocytes $M g$ : tissu testiculaire mésodermique $M g l$ : pièces buceales $n$ : paquet de mitochondries (« noyau accessoire ») $R$ : globule polaire $S p c$ : spermatocytes $S p c_{1}$ : spermatocytes au repos $S p c_{2}:$ spermatocytes au stade pré-meïotique $S_{p c_{1}}$ : divisions de maturation $S_{p g}:$ spermatogonies $S_{p g_{2}}:$ spermatogonies disposées en étoile $S_{p g}$ : mitoses de spermatogonies $S_{p}$ : étapes intermédiaires de la spermiogénèse $S p k$ : noyaux des spermies $S p m$ : spermies $S_{p t}$ : spermatides $T u$ : enveloppe péritonéale du testicule.

Fig. 16 A 25

$E_{p}$ : épithélium du tube séminifère $F z$ : cellules folliculaires $S_{p c_{1}}:$ spermatocytes normaux $S_{p c_{2}}:$ spermatocytes en croissance et spermatocytes géants $S p m$ : spermies $S p t:$ spermatides $S p t_{1}:$ spermatides apparemment uninucléées $S p t_{2}$ : spermatides bi-nucléées.

FIG. 26 ET 27

Ao: aorte $B a$ : ébauche de patte C.a. : corpus allatum C.c. : corpus cardiacum Cgl : ganglion susœesophagien (Cerveau) $F$ : tissu adipeux $F g l$ : ganglion frontal $H y$ : ganglion hypo-cérébral $M$ : bouche $M d$ : intestin moyen $M e p$ : épithélium de l'intestin moyen $N_{p}$ : nervus procurrens $N_{r}$ : nervus recurrens $\mathrm{Nz}$ : cellules neuro-sécrétoires Oes : œsophage $P d r$ : glande pro-thoracique $S p d$ : glandes séricigènes $S g l$ : ganglion sous-esophagien $T:$ corpotentorium $T_{g_{1}}, T h_{2}:$ premier et second ganglions thoraciques. $\operatorname{Tr}:$ première trachée thoracique $Z d:$ proventricule. 


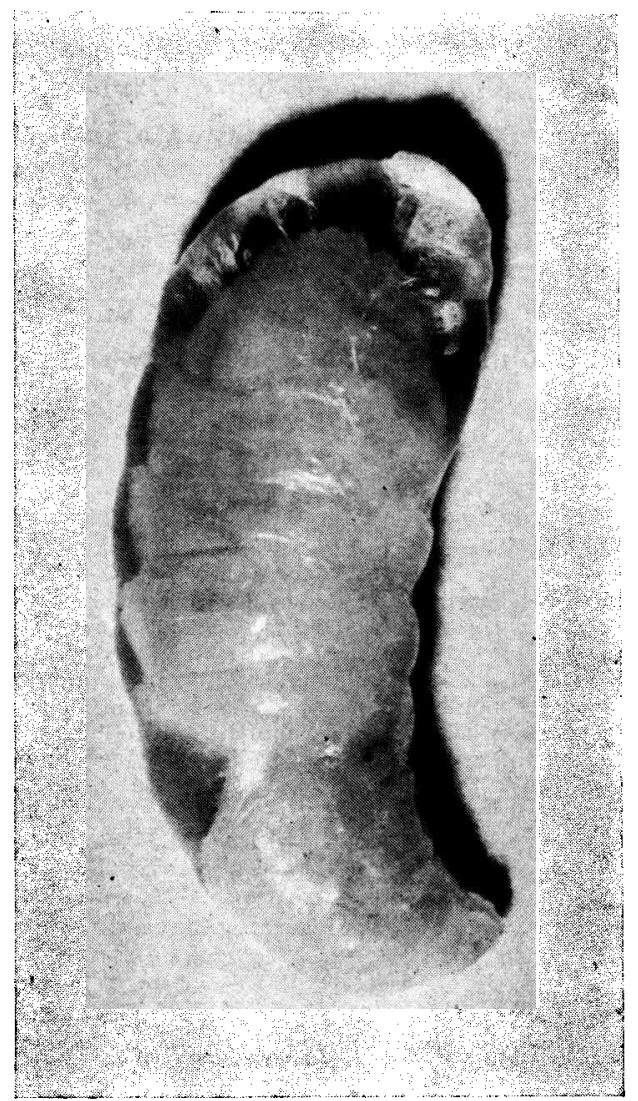

AвB. 1. - Häutungsstörung :

in Verwandlung begriffene Drohnenstreckmade mit abnorm grossem Exuvialflüssigkeitssack

(phot. Hättenschwiler, Liebefeld)

Fig. 1. - Perturbation de la mue :

larve allongée de mâle en train de muer avec sac exuvial anormalement grand. (Photo Hättenschwiler, Liebefeld).

Entwicklungsstadien der Bienenarbeiterinnen. Aus noch ungenügend bekannten Gründen verwandelt sich zuweilen rund die Hälfte von ihnen auch ohne Gespinstunterlage normal. Ob dabei das jeweilige Alter der Streckmaden oder hormonelle Einflüsse eine entscheidende Rolle spielen, soll später diskutiert werden. Jedenfalls steht fest, dass die typischen Drohnenkrüppel fast ausnahmslos aus ältern, verwandlungsbereiten Streckmaden hervorgehen. Dass die hier beschriebenen Häutungsstörungen tatsächlich auf das Fehlen des Larvengespinstes und nicht etwa auf andere Aussenfaktoren zurückzuführen sind, lässt sich experimentell leicht nachweisen. Wiederholt man nämlich den oben skizzierten Versuch unter den genau gleichen Bedingunəgn mit spinnreifen oder spinnenden Arbeiterinnen- und Drohnenlarven, 


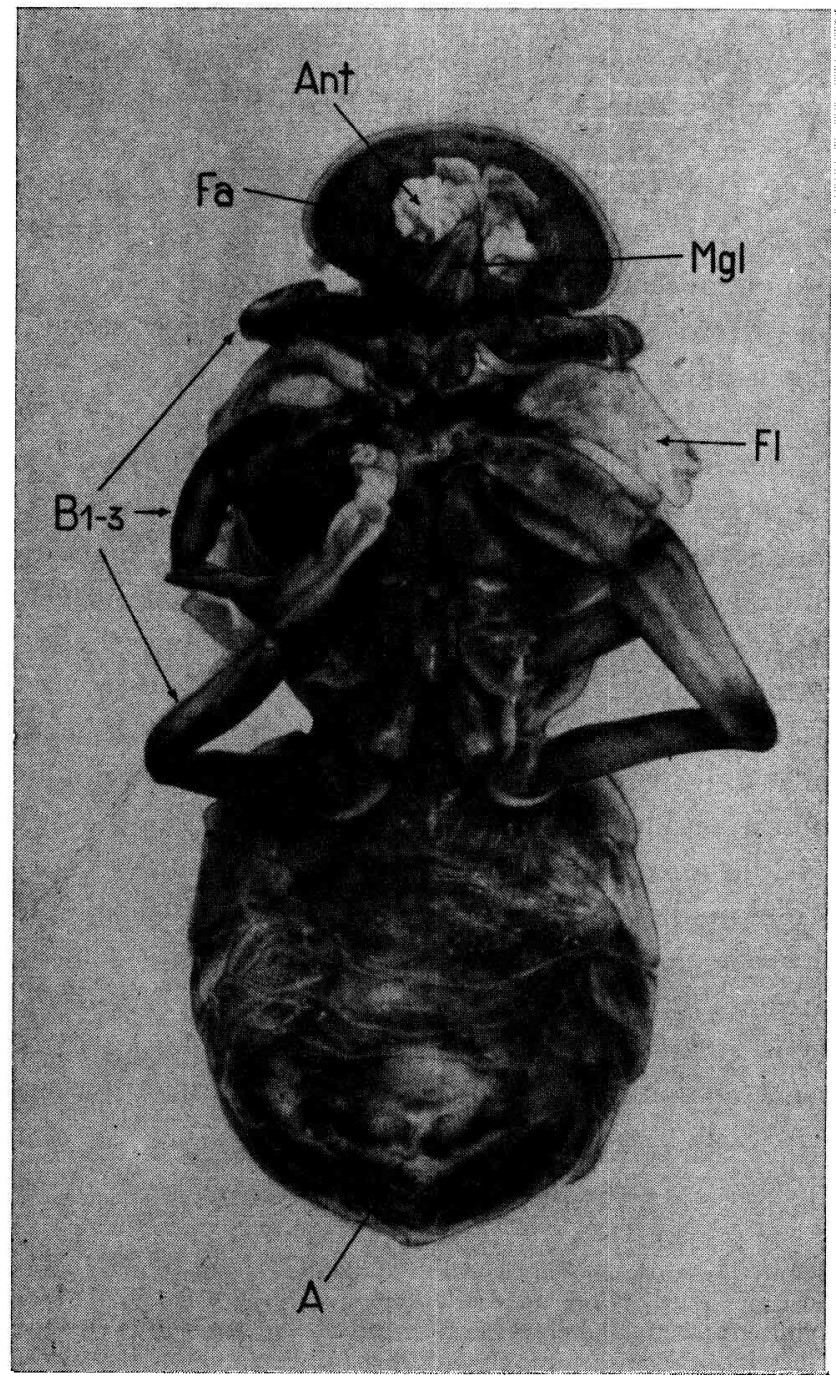

Авв. 2. - Verkrüppelte Drohnenpuppe (Ventralansicht) (phot. Hättenschwiler, Liebefeld)

FIG. 2. - Nymphe de mâle malformée (Vue ventrale) (Photo Hättenschwiler, Liebefeld).

welche den gläsernen Boden der Zuchtschalen alsbald mit einem feinen, dichten Gespinst überziehen, so treten bei den Testtieren keine Entwicklungsstörungen auf. Alle auf dem Gespinst liegenden Maden verpuppen sich im Brutschrank vielmehr ganz normal und es entstehen aus ihnen gut entwickelte, lebensfähige Bienen. Diese eigenen Versuchsergebnisse, die sowohl mit den Befunden von VeLICH (1930) als auch mit den analogen Beobachtungen von Сhurch (1955) bei der Halmwespe Cephus cinctus Nort. übereinstimmen, sprechen meiner Ansicht nach dafür, dass das Larvengespinst auf 
die verpuppungsbereite Streckmade offenbar einen Reiz ansübt, welcher für die Auslösung und den normalen Verlauf der Metamorphosehäutung nötig ist. Vermutlich haben wir es dabei mit Berührungsreizen zu tun, die von bestimmten larvalen Hautsinnesorganen perzipiert werden. Wie Lukoschus (1955) festgestellt hat, besitzen die Bienenlarven zahlreiche kurze Tasthaare, die als Mechanorezeptoren dienen dürften. Sie finden sich in kleinern und grösseren Gruppen ausschliesslich auf der Dorsalseite der Rumpfsegmente, also gerade an jenen Körperstellen, mit welchen die Streckmade in ihrer Wabenzelle dem Kokon anliegt (Fyg, 1956, 1966).

Man frägt sich natürlich sogleich, was der vom Larvengespinst ausgehende Reiz eigentlich bewirkt. Spielt er während der Metamorphosehäutung allfällig nur beim Abstreifen der Exuvie eine Rolle oder beeinflusst dieser Reiz vielleicht auch das sonstige Entwicklungsgeschehen Folgende Beobachtungen, welche die Auswirkungen der Metamorphose-Häutungsstörungen auf die Spermatogenese betreffen, mögen zur Abklärung dieser Frage etwas beitragen. Die histologische Untersuchung von Drohnenstreckmaden, welche im Brutschrank ohne Gespinst aufgezogen wurden und sich entweder gar nicht oder nur unvollständig verpuppten, hat ergeben, dass bei ihnen die Samenbildung ganz abnorm verläuft. Die gleichen Regelwidrigkeiten treten aber auch dann auf, wenn die normalen inkretorischen Verhältnisse im späten Larvenoder frühen Streckmadenstadium experimentell durch postcephale oder postthorakale Ligaturen gestört werden. Diese Feststellung scheint mir für eine kausale Erklärung der abnormen Samenbildung bei der Drohne immerhin recht beachtenswert zu sein und dürfte vielleicht die Anregung zu weitern, eingehenderen Untersuchungen an diesem leicht zu beschaffenden Objekt geben.

\section{MATERIAL UND TECHNISCHES}

Die nachfolgend beschriebenen experimentellen und histologischen Untersuchungen führte ich in den Jahren 1953-1963 an der Bienenabteilung der Eidgenössischen milchwirtschaftlichen Forschungsanstalt Liebefeld bei Bern durch. Die benötigten Drohnen-Entwicklungsstadien konnten jeweils in den Monaten Mai bis Juli geeigneten Brutwaben aus gesunden Völkern des Anstaltsbienenstandes entnommen werden. Um jede Verletzung der sehr emp findlichen ältern Larven und Streckmaden zu vermeiden, wurden die Wände der Wabenzellen mit einer stumpfen Pinzette weitgehend abgetragen und die Versuchstiere sodann möglichst rasch mittelst eines kleinen Spatels in gläserne Petrischalen übertragen. In jeder Schale fanden 6-9 Maden in Seiten- oder Rückenlage Platz, ohne sich gegenseitig zu berühren. Vor dem Auflegen des Deckels wurden auf den Schalenrand drei U-förmige, etwa $1 \mathrm{~mm}$ dicke Metallreiter aufgesetzt, um der Luft den Zutritt zu ermöglichem. Die mit einem dünnen Nylonfaden oder Frauenhaar geschnürten Drohnenlarven setzte ich dagegen einzeln in zweckdienliche, aus Bienenwachs angefertigte flache Becher ein, die sich dafür besser eigneten als Glasschalen. Sämtliche Versuchstiere wurden im Brutschrank bei $35^{\circ} \mathrm{C}$ und einer Luftfeuchtigkeit von 40-60\% gehalten.

Für die histologische Untersuchung wurden die Versuchs-und Kontrolltiere grösstenteils in VAN Leeuwen's Pikrinsäuregemisch ${ }^{1}$ und vereinzelt in Carnoy ${ }^{2}$ fixiert. Die Einbettung

1. Zusammensetzung : 1 \% Pikrinsäure in abs. Äthylalkohol 12 Teile. $40 \%$ iges Formalin 2 Teile, Chloroform 2 Teile, Eisessig 1 Teil.

2. Zusammensetzung : abs. Äthylalkohol $60 \mathrm{ccm}$, Chloroform $30 \mathrm{ccm}$, Eisessig $10 \mathrm{ccm}$. 
erfolgte über Methylbenzoat und Benzol in Paraffin. Zur Färbung der 6-8 $\mu$ dicken Schnitte benützte ich vorwiegend WEIGERT's Eisenhämatoxylin und Eosin oder die Azokarmin-Methode von Heidenhain-Mallory (Romeis, 1948).

\section{DER NORMALE VERLAUF DER SPERMATOGENESE BEI DER HONIGBIENE}

Wie allgemein bekannt ist, entstehen die Drohnen normalerweise parthenogenetisch aus unbefruchteten und die weiblichen Bienen (Königinnen und Arbeiterinnen) biparental aus befruchteten Eiern. Während die diploiden Oogonien in den Eierstöcken der Bienenkönigin 32 Chromosomen (2 n) aufweisen und eine regelrechte Meiose durchlaufen, wobei die Chromosomenzahl auf die Hälfte, also 16 (n) reduziert wird ${ }^{1}$, unterbleibt bei den reifenden Samenzellen eine solche zahlenmässige Reduktion; aus den haploiden Spermatogonien und Spermatocyten entstehen durch eine Aequationsteilung und nach der Abschnürung der Richtungs- oder Polkörperchen Spermatiden und Spermien mit der gleichen Chromosomenzahl ${ }^{2}$. Die Haploidie gilt allerdings nur für die männlichen Keim- und Blastodermzellen, denn wie RisLer (1954) festgestellt hat, treten bei der Drohnenlarve schon frühzeitig in vielen Geweben, so beispielsweise im Mitteldarmepithel, in den Harngefässen und Oenocyten, sowie in den Muskeln, im Fettkörper und in den Labialdrüsen di- und polyploide Zellen auf. Sehr wahrscheinlich hängt diese somatische Polyploidisierung mit dem raschen Wachstum und der gesteigerten Tätigkeit der erwähnten Organe zusammen.

Die Abbildungen 3-15 veranschaulichen nach eigenen Untersuchungen verschiedene Phasen der Spermatocytogenese und Spermiogenese. Sie eignen sich, wie ich ausdrücklich bemerken möchte, nicht zur Auszählung der Chromosomen, sondern dienen als histologische Schnittbilder lediglich zum Vergleich der normalen mit der abnormen Samenbildung, wie sie später beschrieben wird. Wenn wir von der sehr früh erfolgenden und fast noch unerforschten Einwanderung der Urkeimzellen in die mesodermalen Hodenanlagen des Drohnenembryos (Nelson, 1915; Zander, 1916; Snodgrass, 1956) absehen, so spielt sich die ganze Spermatogenese im Verlaufe der Postembryogenese ab und findet mit Ausnahme einer gewissen physiologischen Nachreifung der Spermien in den imaginalen Vesiculae seminales (BISHoP, 1920; RUtTNER, $1966,1968)$ bereits in der zweiten Hälfte der Puppenperiode ihren Abschluss. In den larvalen und pupalen Hodenschläuchen sind nicht alle aufeinanderfolgenden Spermatogenesestadien gleichzeitig vorhanden. Wie die Tabelle 1 zeigt, sind für die einzelnen Entwicklungsstufen des Drohns vielmehr bestimmte Stadien der Samenbildung kennzeichnend.

1. Literatur : Nachtsheim, 1913; SAnderson et HaLe, 1048, 1951, 1951a; WoLf, 1960; RUTrNer, 1968a.

2. Literatur : Meves, 1903, 1907; Giglio-Tos, 1905; DonCaster, 1906, 1907; Mark et Copeland 1907; Nachtsheim, 1913; SANDERSON et HaLL, 1948, 1951, 1951a; Hachinohe et ONISHI, 1952; Wolf, 1960; RUTTNER, 1968. 
TABELLE 1

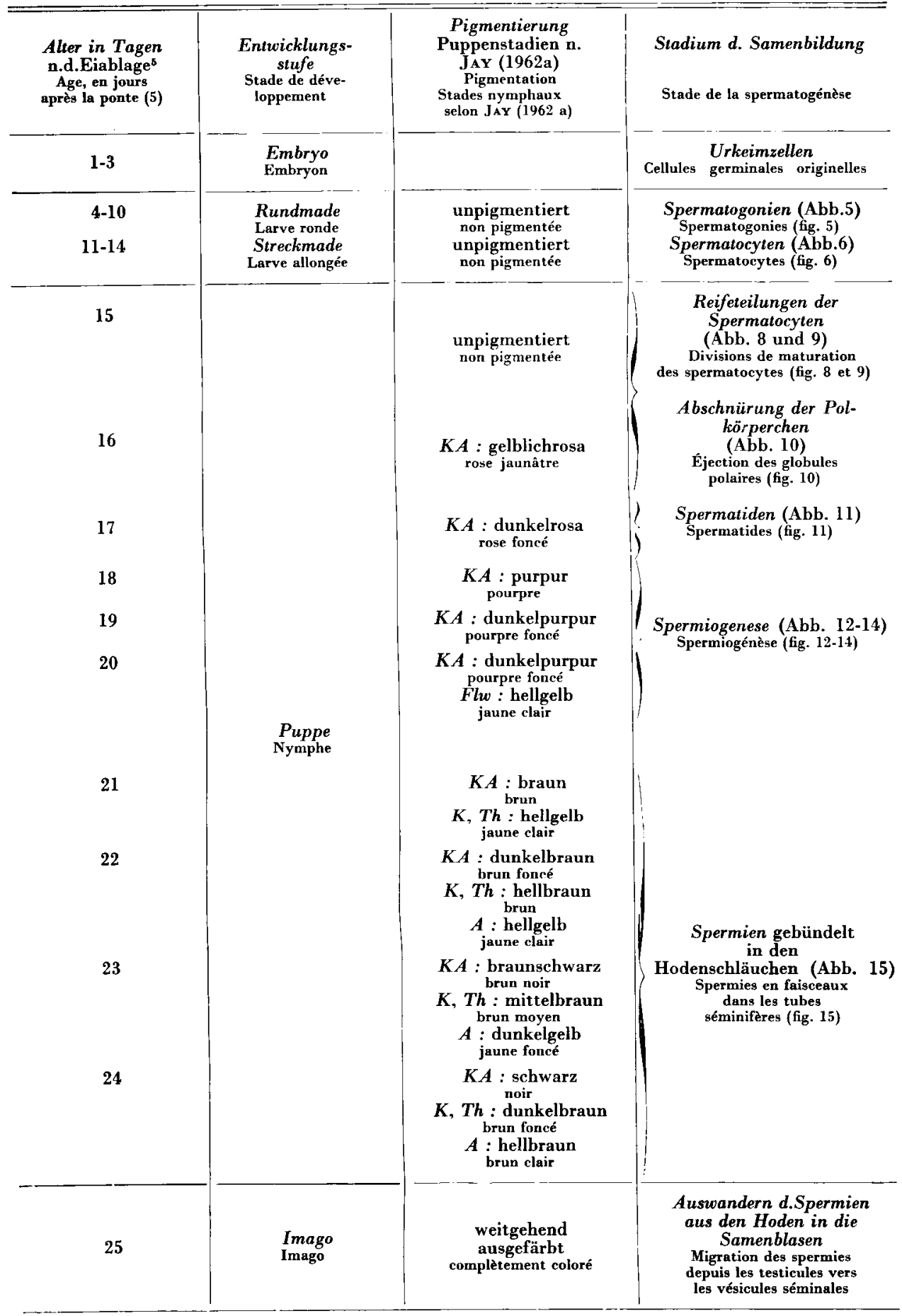

Abkürzungen : Abréviations : $K A$ : Komplexaugen, yeux composés. Flw : Flügelwurzeln, base des ailes. $K$ : Kopf, tête. Th : Thorax. $A$ : Abdomen.

5. Die Entwicklungsdauer der Drohnen ist recht variabel und hängt von verschiedenen Faktoren ab (Jung-Hoffmanv, 1968). Die durchschnittlichen und als Norm geltenden Entwicklungszeiten in der Tabelle 1 stützen sich auf die Angaben von Leuenberger (1954).

5. La durée du développement des mâles est assez variable et dépend de différents facteurs (JuNG-HoFfmaNN, 1968). Les temps moyens de développement considérés comme normaux, figurant dans le tableau 1 sont basés sur les données de LEUENBERGER (1954). 

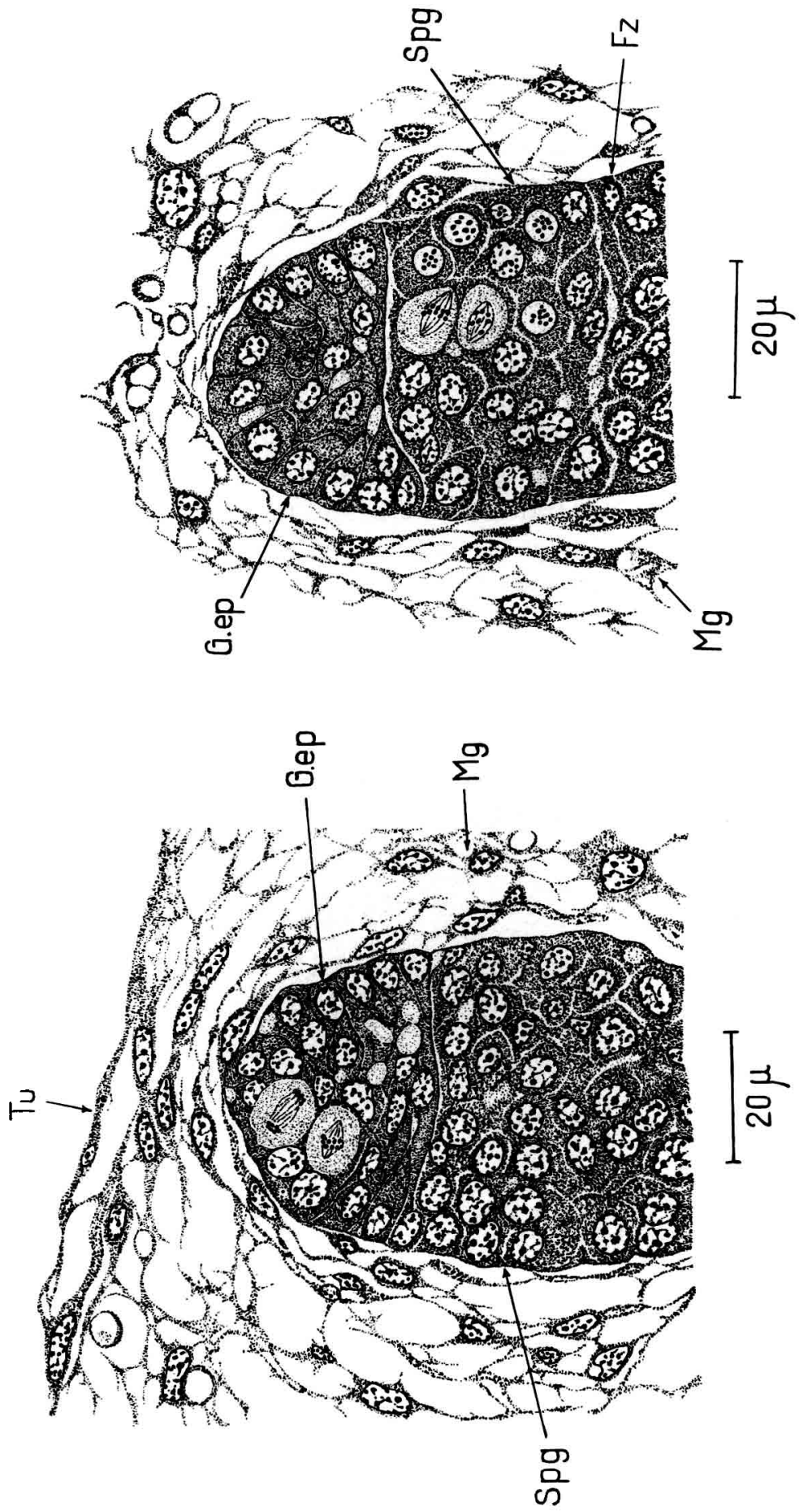

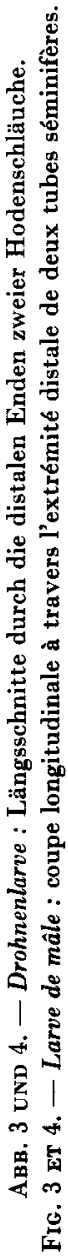


Bei den Rundmaden finden wir am blindgeschlossenen apikalen Ende eines jeden Hodenschlauches das Germinalepithel (Abb. 3 und Abb. 4, G. ep), aus dem die zahlreichen Spermatogonien (Spg) und die anfänglich kleineren Follikelzellen (Fz) hervorgehen. Es bildet einen deutlich begrenzten, zusammenhängenden und kuppenförmigen Zellkomplex. Bei jüngeren und älteren Drohnenlarven kann man im germinalen Epithel recht oft typische Mitosen beobachten (Abb. 3); die sich teilenden Zellen fallen durch ihre Grösse und ihr lichteres Cytoplasma auf. Seltsamerweise ist gerade dieses Keimepithel des Drohns meines Wissens in der bienenkundlichen Literatur bis jetat nie näher beschrieben oder bildlich dargestellt worden. Proximal vom Germarium folgen in allen Testiolen die mit spärlichen Follikelzellen untermischten primären Spermatogonien (Spg), die vorerst noch keine bestimmte Anordnung zeigen, sondern mehr oder weniger dichtgedrängt die Lichtung der Hodenschläuche ausfüllen. Die Ursamenzellen besitzen ein körniges Cytoplasma und einen rundlichen, scharfkonturierten Kern mit feinem Gerüstwerk, welcher neben vielen kleineren meist auch ein oder zwei grössere Chromatinbrocken enthält. Zahlreiche Mitosen (Abb. 4) deuten auf eine rasche Vermehrung hin.

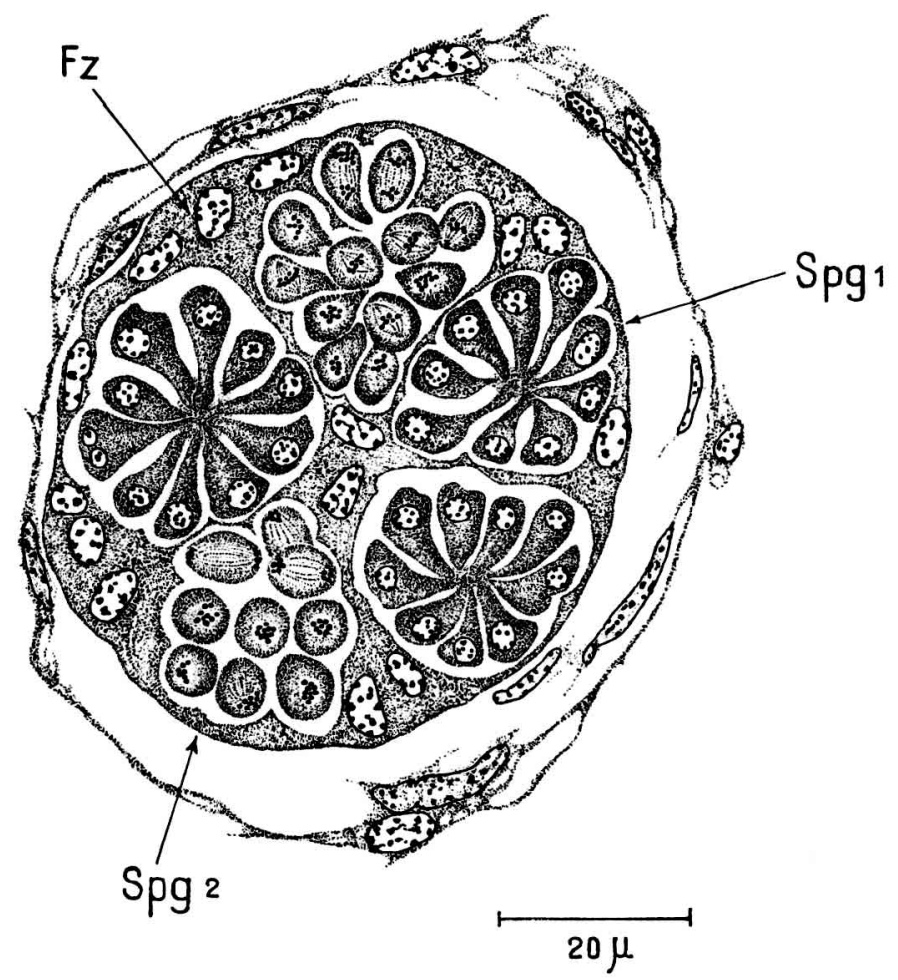

Aвв. 5. - Hodenschlauch einer Drohnenlarve (Querschnitt)

Fig. 5. - Tube sèminifère d'une larve de mâle (coupe transversale). 
Aus den primären Spermatogonien entstehen auf diese Weise die sekundären Spermatogonien (Abb. 5, Spg ${ }_{1}$ ), welche nun nicht mehr regellos im Lumen der Testiolen liegen; sie werden vielmehr durch die stark herangewachsenen Follikelzellrn (Fz) gruppenweise in kugeligen Samenherden vereinigt und bilden in diesen Spermatocysten gewissermassen Rosetten, welche für alle etwas älteren Larvenstadien sehr charakteristisch sind. Diese Gruppierung kommt augenscheinlich dadurch zustande, dass sich die inzwischen kegelförmig gewordenen Spermatogonien in den Samenherden radial anordnen und zwar so, dass ihre zugespitzten Enden dem Zentrum zugewendet sind und hier durch eine homogene Klebmasse (Spindelrestkörper nach BucHNER, 1915) verbunden werden. In dieser Phase der Spermatogenese findet offenbar noch eine weitere Vermehrung der sekundären Spermatogonien statt. Dafür scheinen mir jedenfalls die recht häufigen und in der Regel synchron verlaufenden Mitosen (Abb. 5, $\mathrm{Spg}_{2}$ ) zu sprechen, welche man in vielen Spermatocysten feststellen kann. Bei den reifen, d.h. ausgewachsenen Rundmaden beginnen die nunmehr wieder kugeligen Spermatogonien sichtlich grösser zu werden und verwandeln sich schliesslich in Spermatocyten (Abb. 6, Spc),

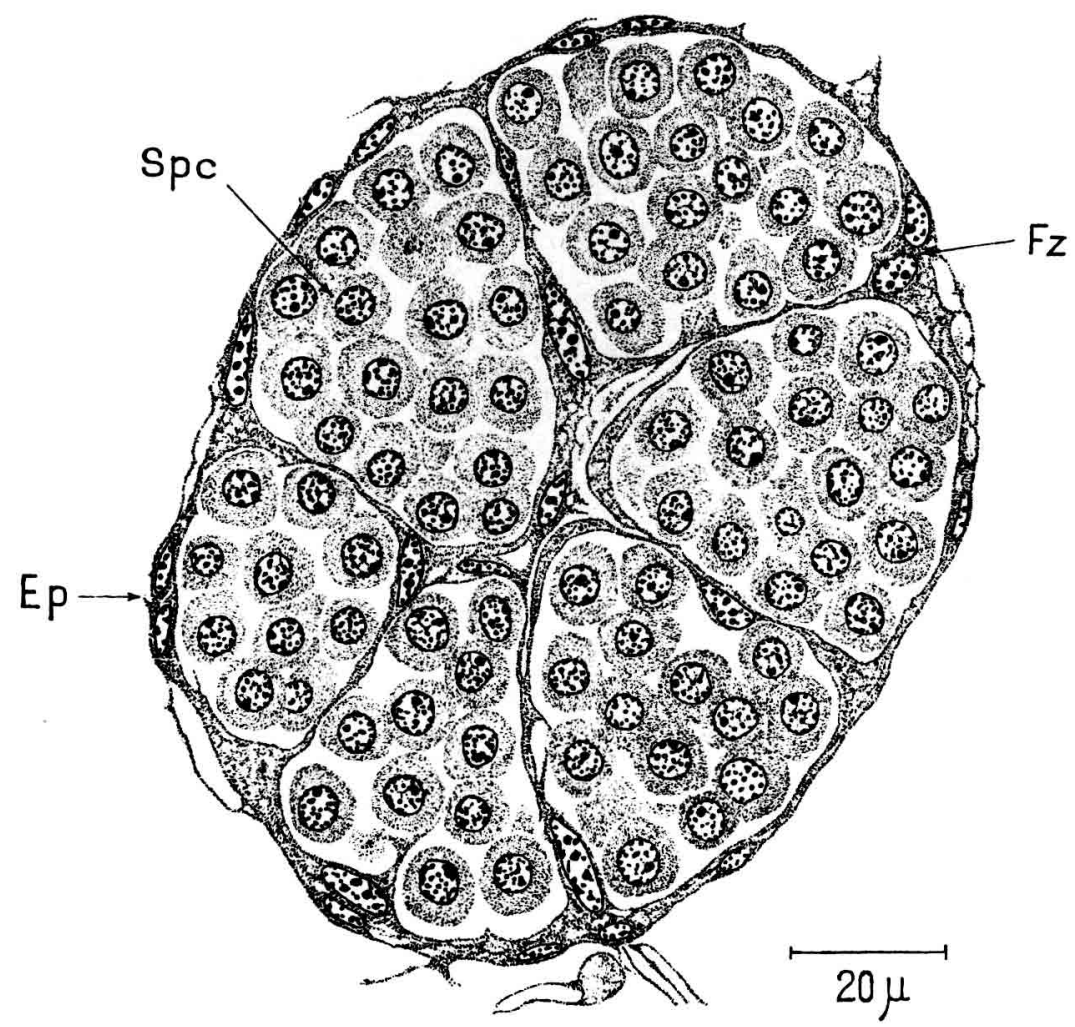

Aв8. 6. - Hodenschlauch einer eintägigen Drohnenpuppe (Querschnitt) Fıg. 6. - Tube séminifère d'une nymphe de mâle de un jour (coupe transversale). 
wie sie für die Streckmaden und unmittelbar nach der Metamorphose für die jüngsten Puppen typisch sind. In dieser Entwicklungsperiode des Drohns sind sämtliche Samenherde in allen Hodenschläuchen mit derartigen Spermatocyten mehr oder weniger prall gefüllt. Nur im obersten Abschnitt der Testiolen verbleiben noch die germinalen Epithelzellen (Abb. 7, G. ep) und einige primäre Spermatogonien (Spg) mit oft stark vakuolisiertem Cytoplasma, die jedoch keine Anzeichen einer Vermehrung mehr erkennen lassen. Ein weiterer Nachschub von jüngern Spermatogenesestadien fehlt also. In diesem Zusammenhang sind noch die losen Zellen (Abb. $7, \mathrm{~L})$ zu erwähnen, welche sich bei

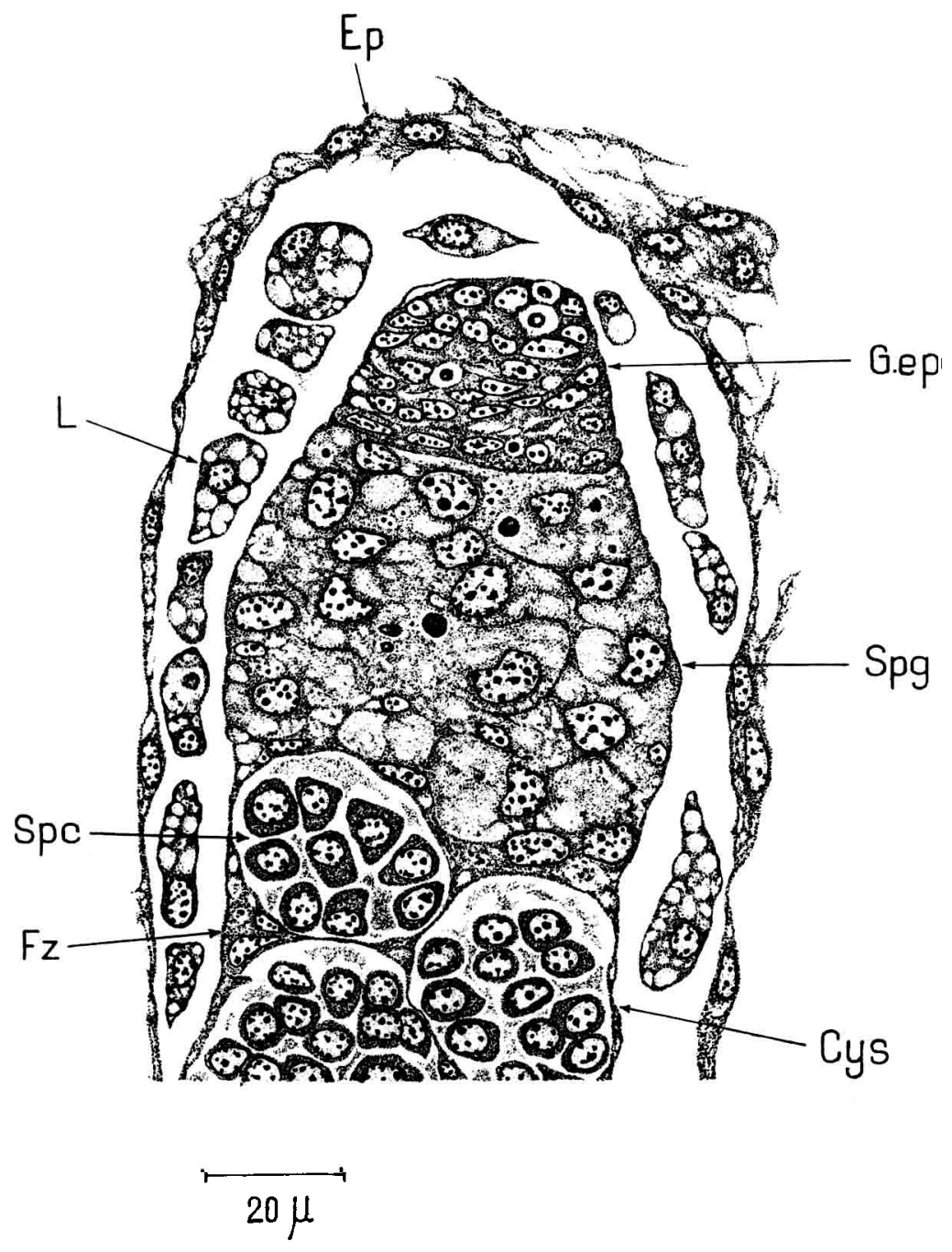

Aв8. 7. - Drohnenstreckmade : Längsschnitt durch das distale Ende eines Hodenschlauches.

Fıg. 7. - Larve allongée de mâle : coupe longitudinale à travers l'extrémité distale d'un tube séminifère. 
den Drohnenpuppen im ganzen Verlaufe der Hodenschläuche, besonders reichlich aber in ihrem distalen Endabschnitt zwischen der dünnen, einschichtigen Testiolenwand $\left(E_{p}\right)$ und dem Samenzellenstrang vorfinden. Es handelt sich dabei um Hämocyten, wie sie auch in den larvalen und pupalen Ovariolen der Bienenköniginnen und Arbeitsbienen vorkommen (Lotmar, 1945; Fyg, Publikation in Vorbereitung). Sie dürften eine trophische Funktion haben, da sie nachweislich viel Glykogen enthalten und wahrscheinlich schon frühzeitig in die Gonaden einwandern, wo sie sich auch mitotisch vermehren.

Kurz nach der Metamorphose beginnen bei den jüngsten, noch völlig unpigmentierten Drohnenpuppen die Reifeteilungen der Spermatocyten

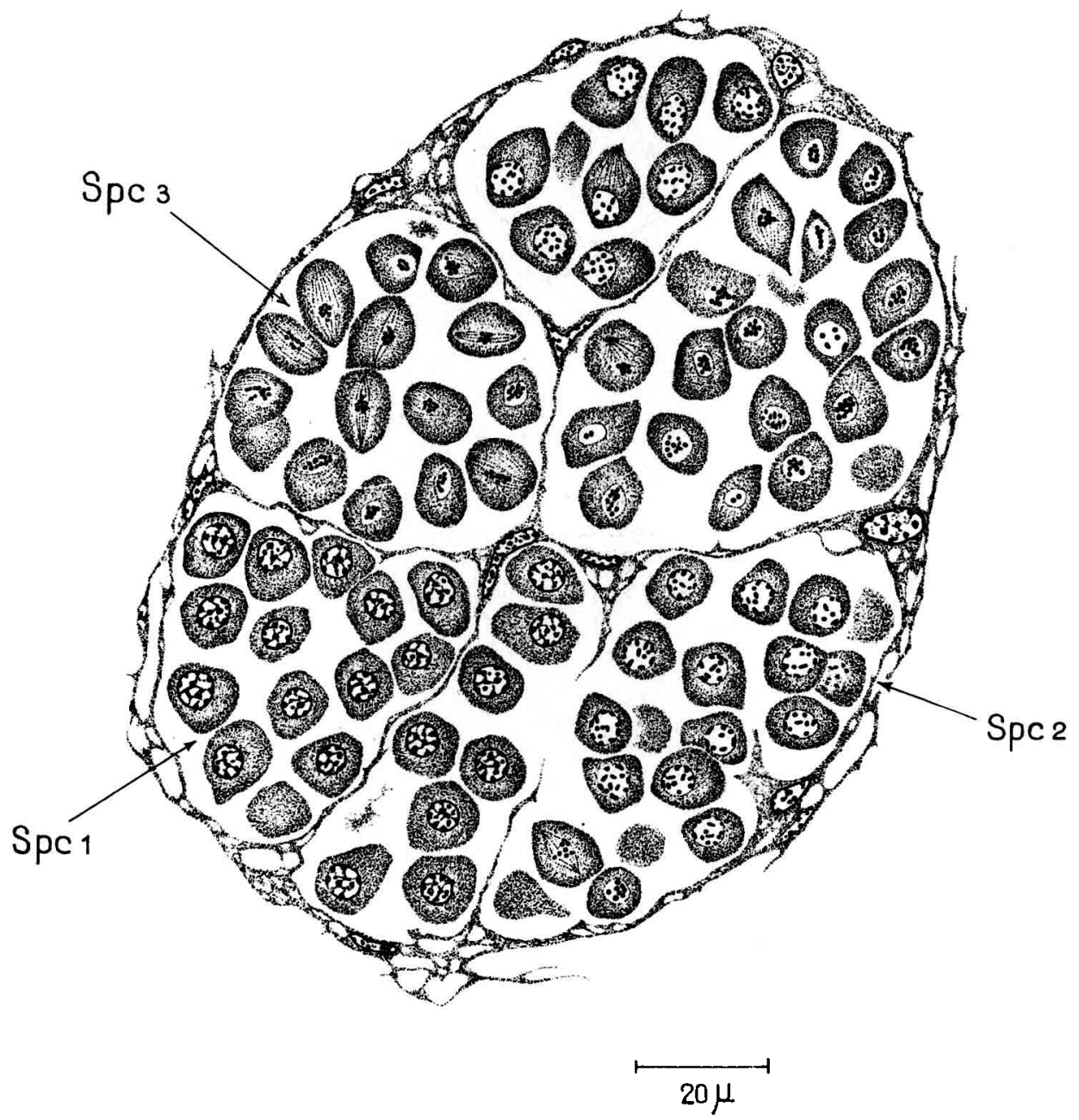

Aв8. 8. - Hodenschlauch einer Drohnenpuppe mit unpigmentierten Komplexaugen (Querschnitt) Fıg. 8. - Tube séminifère d'une nymphe de mâle avec ail composé non pigmenté (coupe transversale). 


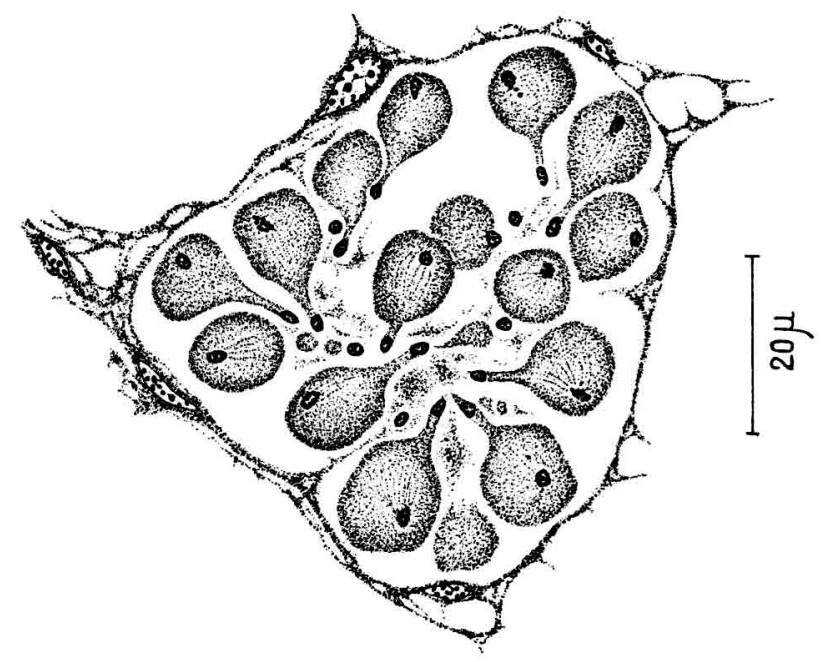

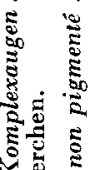

:

कह 응

हू월

ㅇํ응

ड 50

롱

를

जิ

송

और

을

를

ए ए

हैं

胥

올 है

है. 명

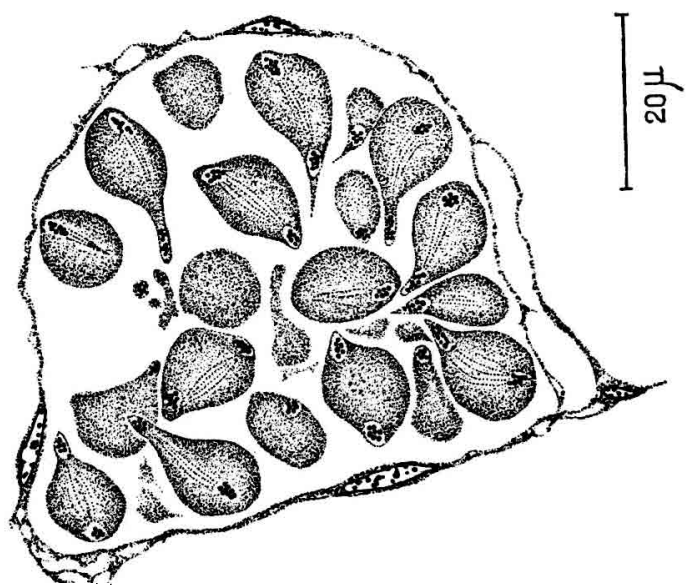

s.

요

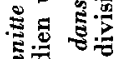

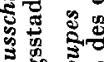

प है 0

1 | 蛋

을

合里

a $a$

照 
(Abb. 8-10), also jene Prozesse der Samenbildung, welche seit jeher besonders gründlich untersucht worden sind. Das geschah nicht nur zur Abklärung der chromosomalen Verhältnisse, sondern wohl auch deshalb, weil die Reifung der männlichen Keimzellen der Honigbiene im Vergleich mit verwandten Insekten gewisse Besonderheiten zeigt (Buchner, 1915; Morgan, 1921; KüнN, 1965; Wніте, 1957); zudem konnten dabei einzelne, von früheren Autoren mitgeteilte Befunde später berichtigt und ergänzt oder anders gedeutet werden (Sanderson et HaLl, 1948, 1951; Wolf, 1960). Als erstes Anzeichen der bevorstehenden Reifeteilungen ist in den Ruhekernen der Spermatocyten (Abb. 8, $\mathrm{Spc}_{1}$ ) eine diakineseartige Kondensierung des Chromatins $\left(\mathrm{Spc}_{2}\right)$ festzustellen. Die meist paarweise vereinigten Chromosomen liegen dann dicht unter der Kernmembran und sollen in diesem Stadium, wie WolF (1960) hervorhebt, besonders leicht zu zählen sein. Schon hier fällt auf, dass in der Regel alle Spermatocyten eines Samenherdes die verschiedenen progressiven Entwicklungsstufen fast gleichzeitig erreichen und vollenden. Das gilt nicht nur für die Prophase, sondern auch für die nun folgenden Reifeteilungen (Abb. 8, $\mathrm{Sps}_{3}, \mathrm{Abb} .9$ und 10), welche nach den eingehenden Untersuchungen von WoLF (1960) offenbar weniger kompliziert verlaufen, als bislang angenommen und in der Fachliteratur gemeinhin dargestellt wurde. Gestützt auf die Befunde von Meves (1907) und Nachtsheim (1913) war man nämlich bis vor kurzem ganz allgemein der Ansicht, dass beim Drohn trotz des Fehlens einer zahlenmässigen Reduktion der Chromosomen ebenfalls zwei Reifeteilungen stattfinden, wobei die erste allerdings abortiv verlaufe, d.h. nach der Ausbildung einer intranukleären bipolaren Spindel ohne eigentliche Kernteilung wieder rückgängig gemacht werde und lediglich zur Entstehung einer peripheren, kernlosen Plasmaknospe führe, welche mit der Spermatocyte lose verbunden bleibe. Obwohl bereits Doncaster (1906) darauf hingewiesen hat, dass er in seinen Präparaten keine solche Knospenbildung und nur eine einzige, äquationelle Reifeteilung beobachten konnte, vergingen immerhin noch mehr als 50 Jahre, bis WoLF (1960) durch eine sorgfältige Nachprüfung die Richtigkeit dieser Befunde von Doncaster bestätigte. Wolf beschreibt die einzelnen Phasen des Reifungsprozesses sehr ausführlich und kommt zum Schluss, dass eine abortive Reifeteilung der Spermatocyten im Sinne von Meves nicht existiert. In Wirklichkeit erfolgt nur eine Aequationsteilung ohne vorgängige Reduktion der Chromosomenzahl, so dass man in diesem Falle eigentlich gar nicht von einer richtigen Meiose sprechen kann. Die Reifeteilungen in den männlichen Gonaden der Honigbiene (Abb. 9 und 10), welche offenbar ziemlich rasch verlaufen und nach HAchinone et ONISHI (1952) wahrscheinlich weniger als 10 Studen beanspruchen, zeigen noch eine weitere Besonderheit. Aus jeder Spermatocyte entstehen nicht wie gewöhnlich vier oder wie bei der Hornisse zwei Spermatiden (Meves et Duesberg, 1908), sondern nur eine grosse Spermatide (Abb. 11, Spt) und ein kleiner, kernhaltiger Richtungs- oder Polkörper (Abb. 11, R). Obschon diese plasmaarmen, 


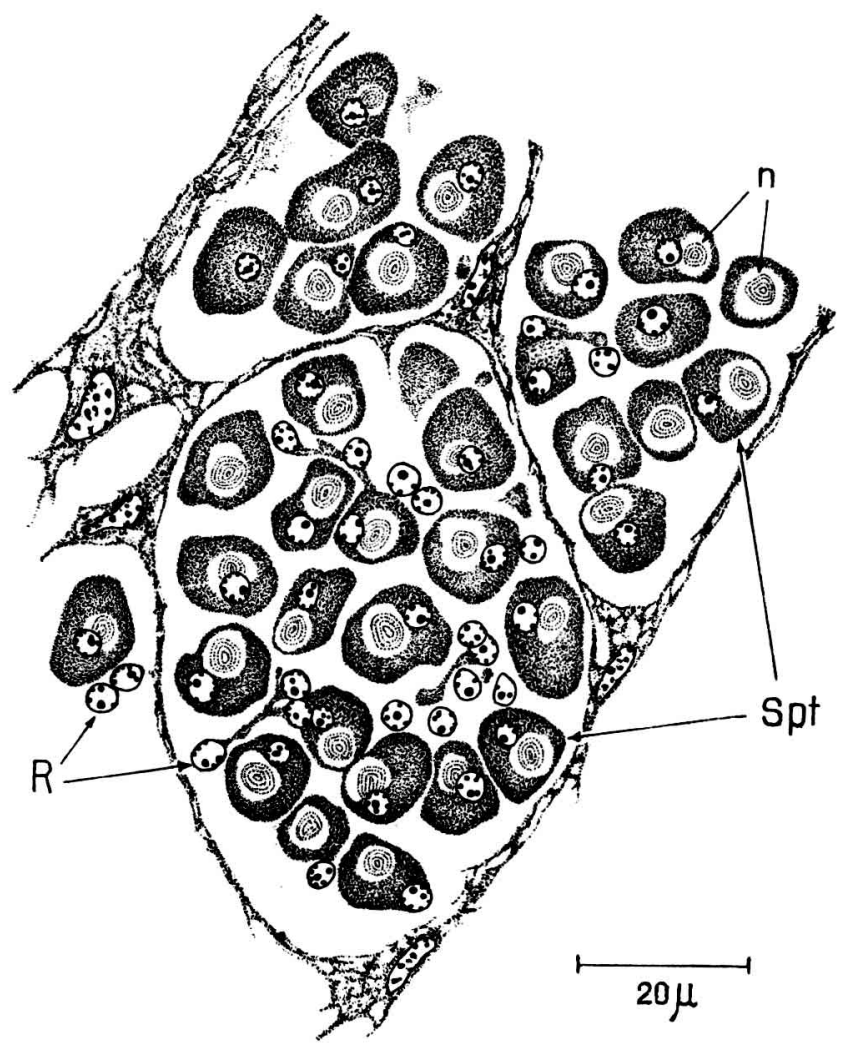

Aв8. 11. - Normale Spermatiden einer Drohnenpuppe mit dunkellila gefärbten Komplexaugen FIG. 11. - Spermatides normales d'une nymphe de mâle avec ail composé au stade de coloration lilas foncé.

aber hinsichtlich der Chromosomenzahl äquivalenten Polkörperchen rudimentären Zellen gleichen, wachsen sie nach der Abschnürung anfänglich doch noch etwas heran; sie gehen dann jedoch im weitern Verlaufe der Spermienbildung zugrunde und werden jedenfalls nicht, wie JEGEN (1919) behauptet hat, bei der Begattung der Bienenkönigin mit dem Samen in die weiblichen Geschlechtswege übertragen.

Bei den etwa 3 bis $3 \frac{1}{2}$ Tage alten Drohnenpuppen, welche an ihren blassrötlichen bis purpurfarbigen Komplexaugen zu erkennen sind, beginnt in der Regel die Spermiogenese, d.h. die Umwandlung der Spermatiden in Spermien. Soweit ich beurteilen kann, sind gerade diese Vorgänge der Samenbildung bei der Honigbiene bis jetzt noch nicht so gründlich studiert und beschrieben worden wie die vorausgehende Spermatocytogenese. Aus diesem Grunde dürfte es angezeigt sein, hier wenigstens einige Abbildungen beizufügen, welche fünf charakteristiche Stadien der Spermiogenese (Abb. 11-15) darstellen. Sie veranschaulichen die tiefgreifenden Form- und Strukturänderungen, welche die Spermatiden bei der Umwandlung in Samenfäden 


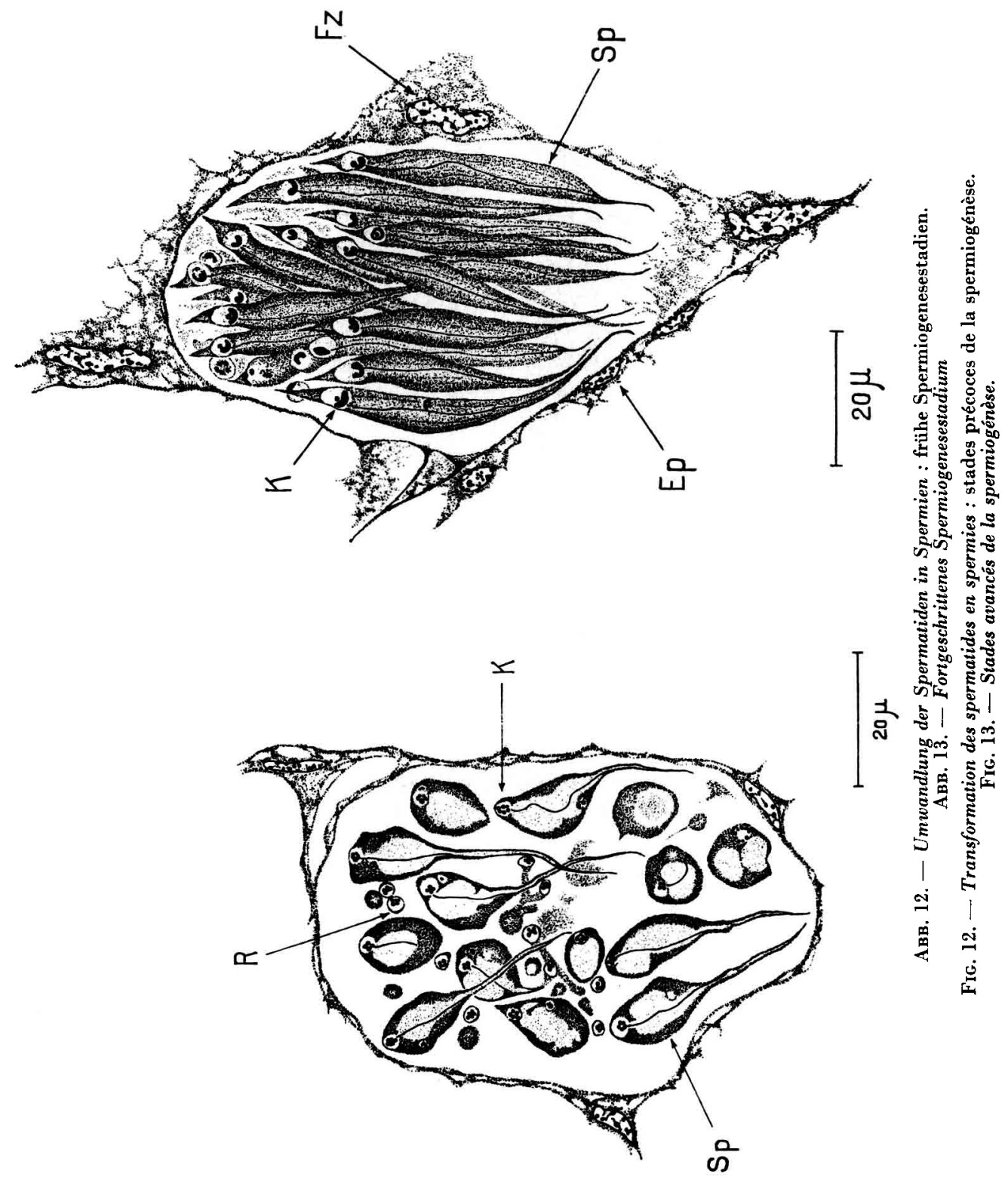




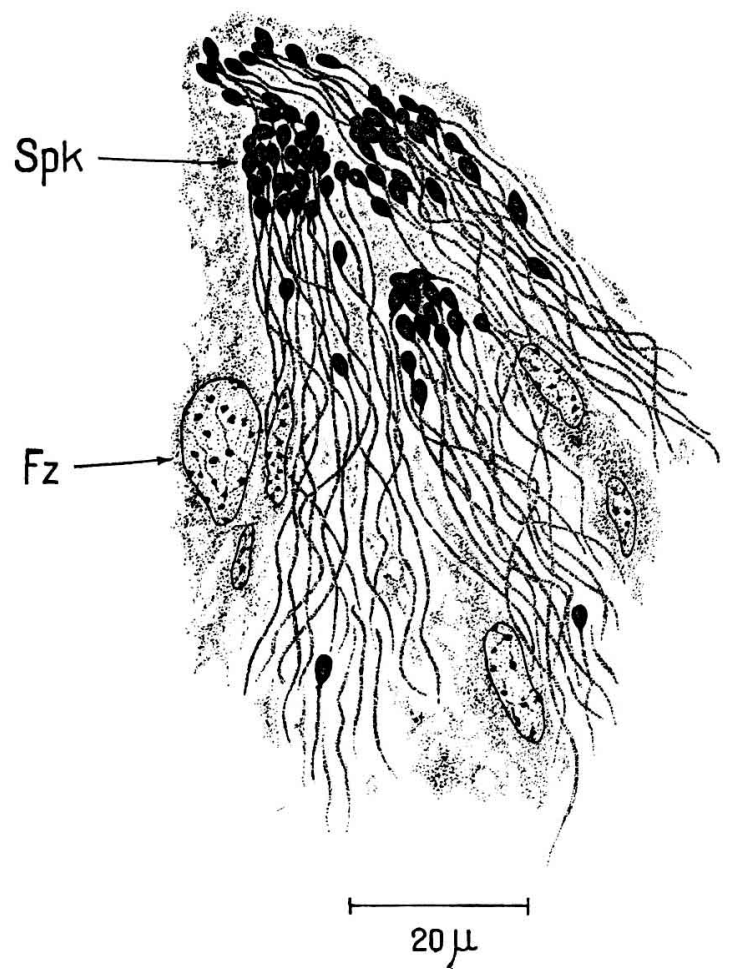

Aвв. 14. - Fast fertige Spermien mit kugeligen Köpfen

FIG. 14. - Spermies presque achevées avec têtes rondes.

durchmachen und bedürfen kaum einer nähern Erklärung. Im Rahmen der vorliegenden Mitteilung genügt es, darauf hinzuweisen, dass sich diese Umformung normalerweise in ungefähr 2 bis 3 Tagen vollzieht. Bei den fünf- bis sechstägigen Puppen ist die Spermiogenese meist beendet und sämtliche Hodenschläuche sind dann mit gebündelten Samenfäden (Abb. 15) prall gefüllt. Später wandern die Spermien aus den Gonaden durch die Samenleiter (Vasa deferentia) in die Samenblasen (Vesiculae seminales) des männlichen Fortp flanzungsapparates, wo sie bis zum Augenblick der Ejakulation verbleiben. Die Auswanderung der Samenfäden aus den Hoden soll nach Bishop (1920) schon zwei Tage vor dem Ausschlüpfen der Drohnen aus ihren Wabenzellen beginnen. In Uebereinstimmung mit den Beobachtungen von Kurennor (1953) und Mindt (1962) konnte ich diesen Vorgang dagegen erst bei den etwa 2 bis 3 Tage alten Imagines feststellen. Die Drohnen sind jedoch zu dieser Zeit noch nicht geschlechtsreif. Das ist frühestens 8-12 Tage nach dem Schlüpfen der Fall (Kurennoi, 1953; Snodgrass, 1956; Mindt, 1962; Ruttner, 1966, 1968). Die Spermien müssen nämlich in den Vesiculae seminales vorerst noch eine physioloyische Nachreifung durchmachen, indem sie aus dem sezernie- 


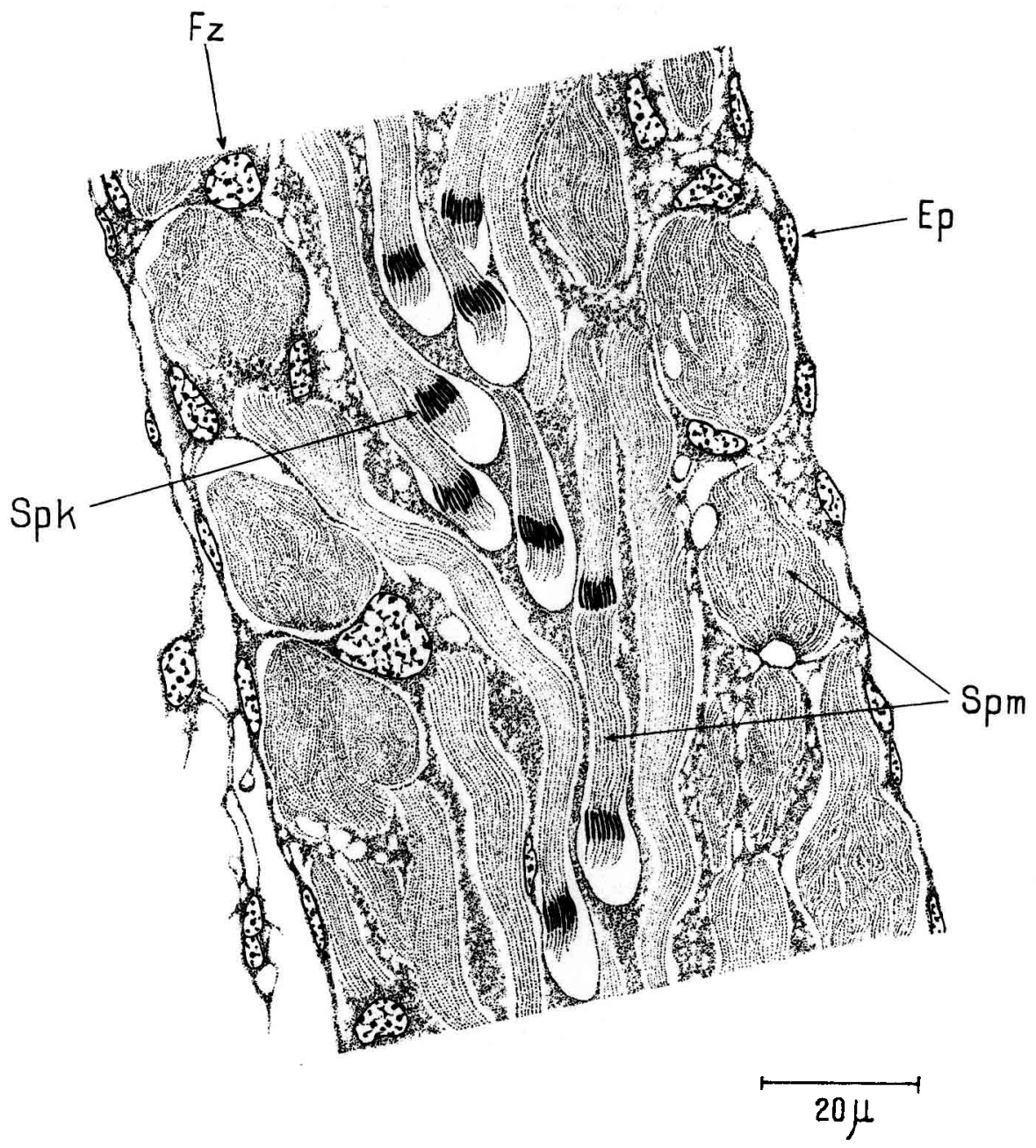

Aвв. 15. - Hodenschlauch einer älteren Drohnenpuppe (Längsschnitt)

Fig. 15. - Tube séminifère d'une nymphe de mâle âgée (coupe longitudinale).

renden Samenblasenepithel vermutlich gewisse Stoffe aufnehmen, welche ihre Aktivität steigern. Dieser Prozess ist allerdings biochemisch noch völlig unabgeklärt.

\section{DER ABNORME VERLAUF DER SPERMATOGENESE}

\section{A. - Verlauf}

Bei der histologischen Untersuchung von 19 unmittelbar hinter dem Kopf oder postthorakal geschnürten und bei 44 gesunden, im Thermostat 
aufgezogenen Drohnenstreckmaden, welche sich im Zeitpunkt der Metamorphose infolge des fehlenden Gespinstes entweder gar nicht oder nur unvollkommen häuten und verpuppen konnten, stellte ich, wie bereits erwähnt, einen

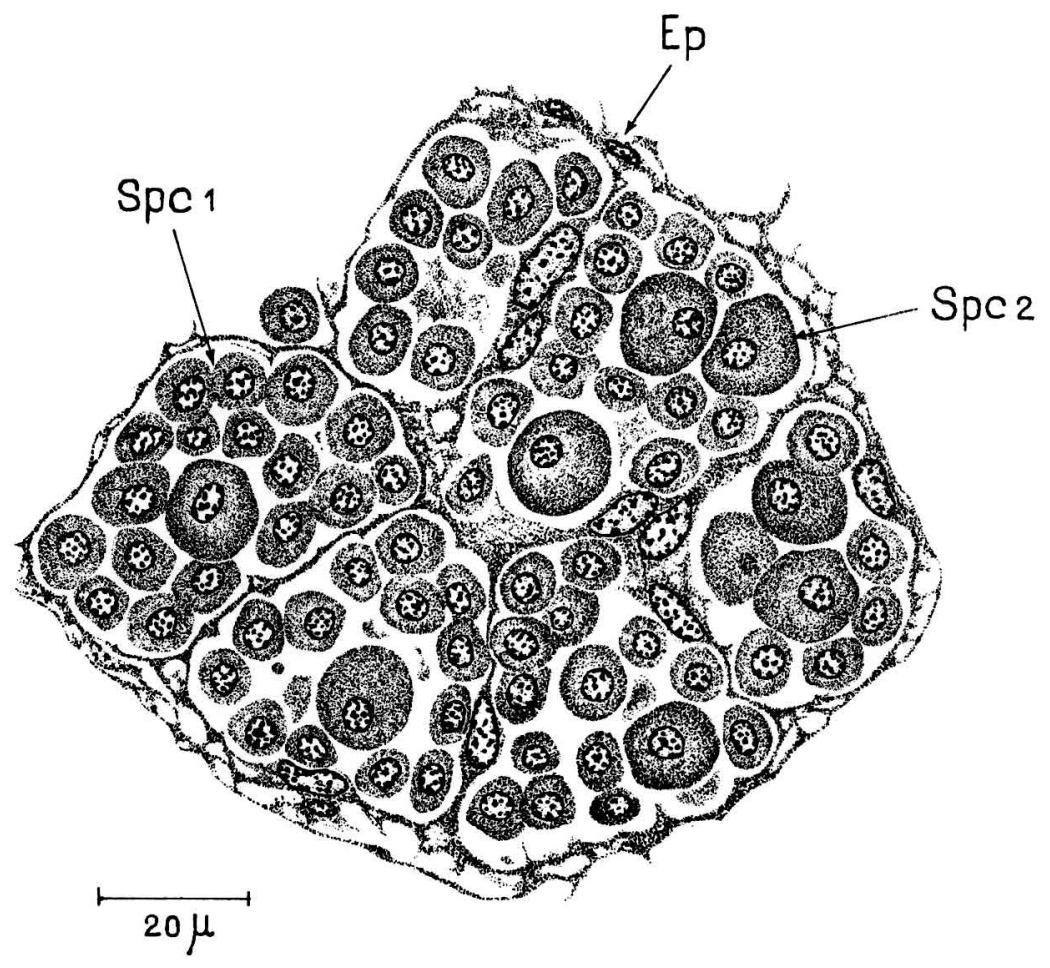

Авв. 16. - Erstes Stadium der abnormen Spermatogenese

FIg. 16. - Premier stade d'une spermatogênèse anormale.

gleichartig abnormen Verlauf der Spermatogenese fest. In allen diesen Fällen wuchsen in vielen Samenherden einzelne oder mehrere Spermatocyten auffallend rasch und stark heran (Abb. 16-18, $\mathrm{Spc}_{2}$ ). Wie die drei Schnittbilder deutlich erkennen lassen, beruht das Wachstum dieser Riesenspermatocyten in erster Linie auf einer oft enormen Volumzunahme des Cytoplasmas, während der Kerndurchmesser kaum merklich zunimmt. Das geht auch aus der Tabelle 2 hervor, welcher 158 Messungen zugrunde liegen.

Das Durchmesserverhältnis von Kern und Zelle verschiebt sich also in wenigen Tagen von $1: 1.85$ auf maximal $1: 5.75$ oder mit andern Worten : während der Kerndurchmesser durchschnittlich nur um etwa $17 \%$ zunimmt, kann diese Steigerung beim Zellendurchmesser bis $258 \%$ betragen. Dadurch wird der Unterschied zwischen den Riesenspermatocyten (Abb. 17, Spc $\mathbf{S}_{2}$ ) mit ihrem anfänglich homogenen, später mehr fibrillär strukturierten Protoplasma und den übrigen Samenzellen (Abb. 16 und 17, $\mathrm{Spc}_{1}$ ) ausserordentlich prägnant 


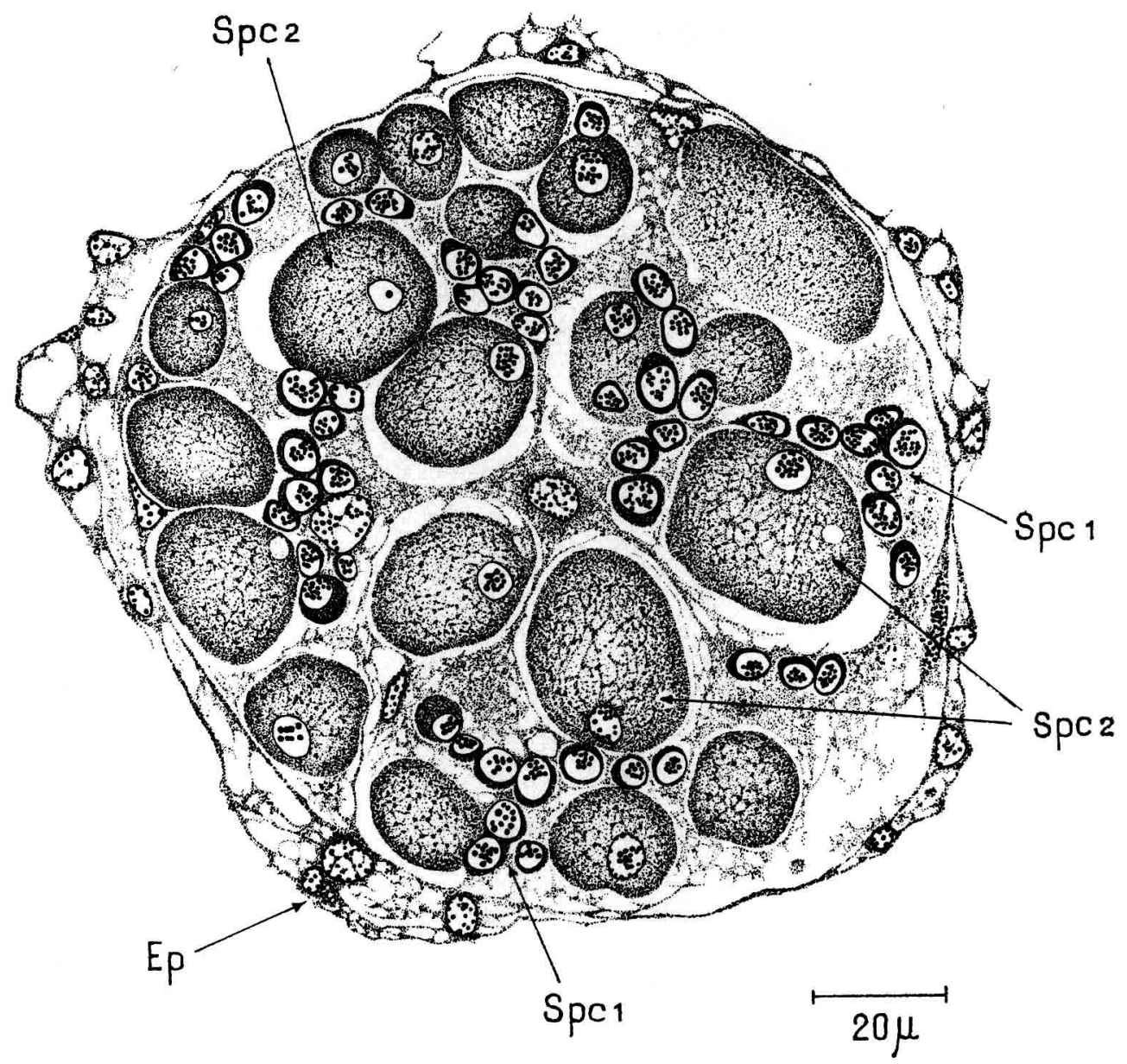

Aвв. 17. - Fortgeschrittenes Stadium der abnormen Spermatogenese mit zahlreichen Riesenspermatocyten Frg. 17. - Stade avancé de la spermatogénèse anormale avec nombreux spermatocytes gêants.

TabelLe 2. - Grössenverhältnisse der normalen und abnormen Spermatocyten

Tablead 2. - Proportions des spermatocytes normaux et anormaux

\begin{tabular}{|c|c|c|c|}
\hline & $\begin{array}{c}\text { mittlerer } \\
\text { Kerndurchmesser } \\
\begin{array}{c}\text { Diamètre moyen } \\
\text { du noyau }\end{array}\end{array}$ & $\begin{array}{c}\text { mittlerer } \\
\text { Zelldurchmesser } \\
\text { Diamètre moyen } \\
\text { de la cellule }\end{array}$ & $\begin{array}{l}\text { Verhältnis Kern- } \\
\text { Zellendurchmesser } \\
\text { Rapport des diamètres } \\
\text { noyau / cellule }\end{array}$ \\
\hline $\begin{array}{l}\text { Normale Spermatocyten } \ldots \ldots \ldots \\
\text { Spermatocytes normaux. }\end{array}$ & $5,2 \mu$ & $9,8 \mu$ & $1: 1,85$ \\
\hline $\begin{array}{l}\text { Heranwachsende Spermatocyten } \\
\text { Spermatocytes en croissance. }\end{array}$ & $5,2 \mu$ & $14,4 \mu$ & $1: 2,75$ \\
\hline $\begin{array}{l}\text { Grōsste Riesenspermatocyten } \ldots \\
\text { Plušgrands spermatocytes géants. }\end{array}$ & $6,1 \mu$ & $35,1 \mu$ & $1: 5,75$ \\
\hline
\end{tabular}




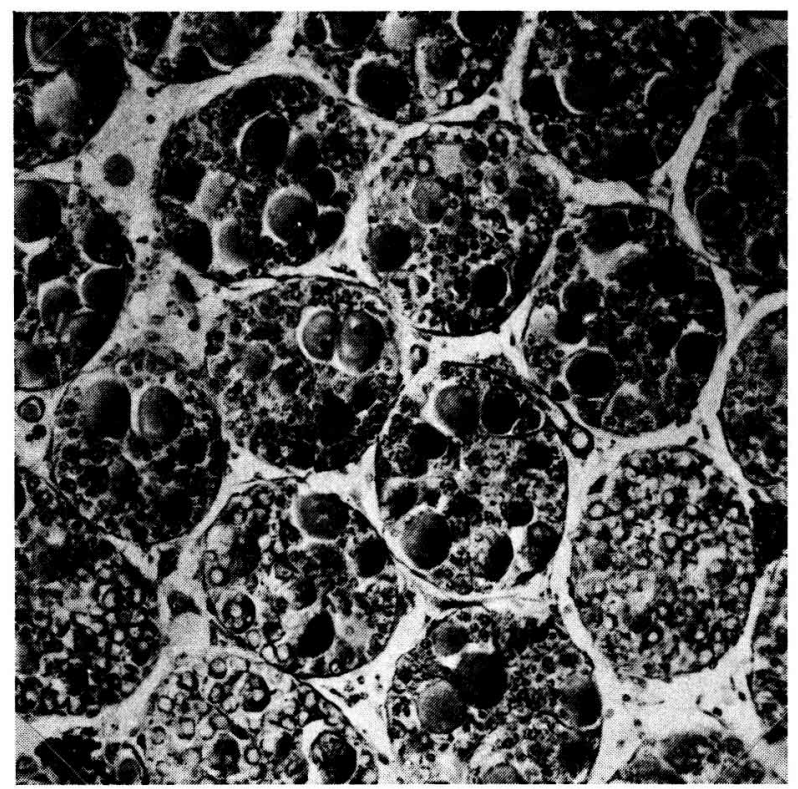

Aвв. 18. - Schnitt durch den Hoden einer Drohnenpuppe mit abnormer Spermatogenese (Mikrophot. Hättenschwiler, Liebefeld)

Fic. 18. - Coupe à travers les testicules d'une nymphe de mâle avec spermatogênèse anormale (Microphoto Hättenschwiler, Liebefeld).

und man gewinnt den Eindruck, dass die letzteren im verbleibenden Raum der Spermatocysten immer dichter zusammengedrängt werden. Trotz dieser Divergenz der beiden Zelltypen zeigen ihre Kerne in der Folge ganz analoge Veränderungen, welche mindestens im Prinzip an die entsprechenden Vorgänge bei der ordentlichen Samenbildung erinnern. Wie in der Prophase der normalen Reifeteilung (Abb. 8, $\mathrm{Spc}_{2}$ ) erfolgt in den Kernen zuerst eine Kondensierung des Chromatins in Form von kleinen Kügelchen (Abb. 17). In einzelnen Riesenspermatocyten treten sodann Mitosen mit deutlich sichtbaren Spindeln auf (Abb. 19, a). Obwohl sie nicht häufig zu beobachten sind, sprechen diese indirekten Kernteilungen doch dafür, dass auch die abnorm grossen Samenzellen die Fähigkeit zur Karyokinese besitzen. Eine anschliessende Zellteilung oder eine Abschnürung eines Richtungskörpers konnte ich aber bis jetzt nie mit absoluter Sicherheit feststellen. Es entstehen vielmehr zwei - bis vierkernige Riesenzellen (Abb. 19, b und Abb. 20, b, c), deren Cytoplasma mehr oder weniger vakuolisiert ist und vielfach fädige Strukturen aufweist, die oft wie Ueberbleibsel von uni - und bipolaren Spindeln aussehen. Aehnliches geschieht meist synchron auch in den normal - und mittelgrossen Spermatocyten (Abb. 21, Spc 1 und $\mathbf{S p c}_{2}$ ). In ihrem Zelleib treten zunächst ebenfalls Vakuolen auf, welche diesen Samenzellen einen ungewöhnlichen Aspekt verleihen. Es folgt dann ein Stadium (Abb. 22), das sich hinsichtlich der Kernstruktur kaum 
von der Prophase der typischen Reifeteilungen (Abb. 8, $\mathrm{Spc}_{2}$ ) unterscheidet. Für das weitere Geschehen trifft das jedoch nicht mehr zu. Gewiss spielen sich in vielen dieser Zellen auch noch richtige Mitosen ab (Abb. 23, a). Die dabei entstehenden, auffallend kleinen Tochterkerne verbleiben aber stets im Zelleib. Wie bei den Riesenspermatocyten kommt es also nicht oder doch nur selten zur Bildung und Abschnürung von kernhaltigen Polkörperchen (Abb. 23, b). Trotzdem dürfte es sich bei den nun vorliegenden Samenzellen (Abb. 24) um Spermatiden handeln, welche allerdings in ihrem Bau erheblich von der Norm abweichen. Um das zu erkennen, genügt es, die Abbildungen 11 und 24 zu vergleichen. Die normalen Spermatiden der Honigbiene (Abb. 11, Spt) besitzen nur einen einzigen, relativ grossen Kern. Ausserdem finden wir in einer Vakuole des fast homogenen Cytoplasmas immer einen dichten Mitochondrienknäuel (n), den sogenannten « Nebenkern » (Meves, 1900), welcher in guten Eisenhämatoxylinpräparaten meist auch ohne Spezialfärbung deutlich zu sehen ist. Zwischen den Spermatiden liegen die abgeschnürten, plasmaarmen Polkörperchen (R), die sich öfters zu kurzen Strängen verbinden. Die abnormen Spermatiden (Abb. 24), die aus den ursprünglich kleinbleibenden Spermatocyten (Abb. 16, $\mathrm{Spc}_{1}$ ) hervorgehen, fallen schon bei schwächerer Vergrösserung durch besonders grosse Vakuolen in ihrem Plasma auf. Sie unterscheiden sich von den normalen Spermatiden (Abb. 11, Spt) aber vor allem dadurch, dass sie

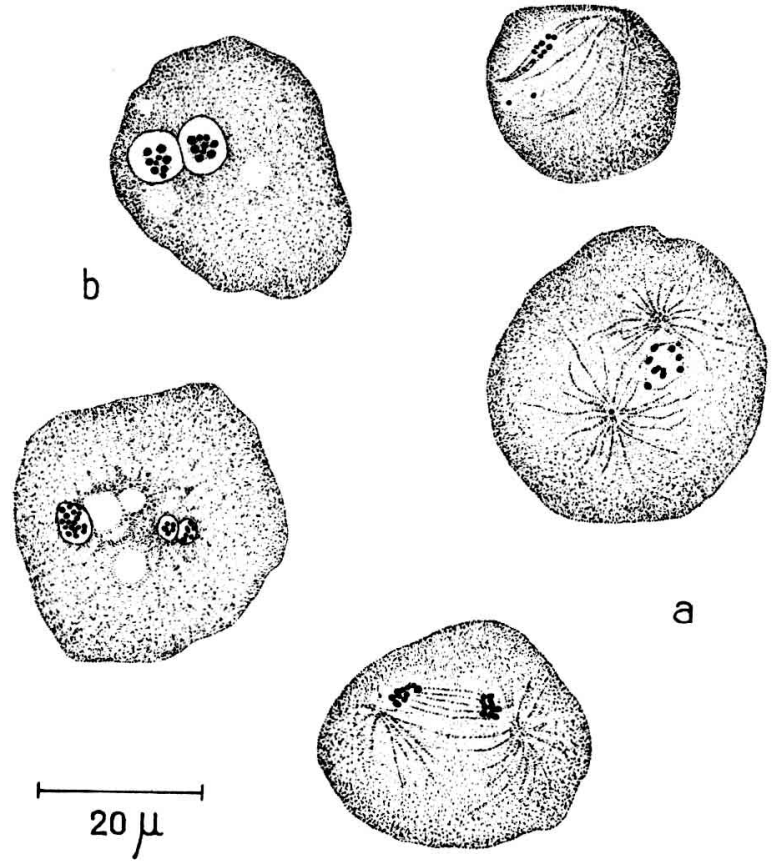

Aв8. 19. - Riesenspermatocyten : Mitosestadien

FIG. 19. - Spermatocytes géants : stades de mitose. 
nicht nur einen Kern, sondern mindestens deren zwei besitzen und zwar deshalb, weil bei ihnen im Verlaufe der Reifeteilung (Abb. 23) ordentlicherweise kein Tochterkern als Richtungskörper abgestossen wird. Gewiss beobachtet man in Schnittpräparaten häufig derartige Spermatiden, welche scheinbar nur einen Kern enthalten (Abb. 24, $\mathrm{Spt}_{1}$ ). In lückenlosen Schnittserien gelingt es jedoch fast immer, bei der vergleichenden Durchsicht der benachbarten Schnitte den angeblich fehlenden zweiten Kern aufzufinden. Auch mehrkernige abnorme Spermatiden sind gar nicht so selten, was darauf hindeutet, dass in diesen Samenzellen - ähnlich wie in den Riesenspermatocyten (Abb. 20, c) - zuweilen ebenfalls mehr als eine Kernteilung erfolgt. Unabgeklärt ist die Frage des Nebenkerns der abnormen Spermatiden. In Präpara-

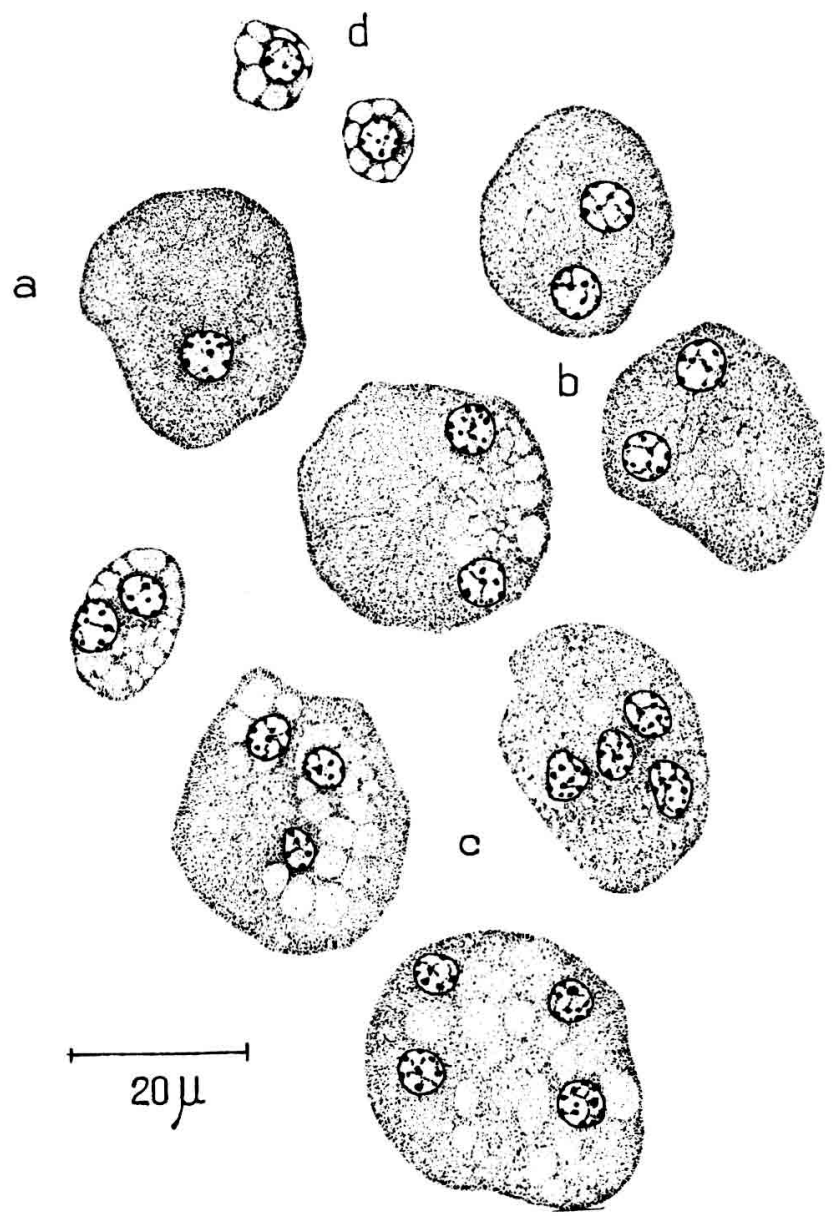

ABB. 20. - Ein- und mehrkernige Riesenspermatocyten (a-c) d : zum Vergleich Spermatocyten von normaler Grösse

Fig. 20. - Spermatocytes géants avec un ou plusieurs noyaux (a-c); d, à titre de comparaison, spermatocytes de taille normale. 


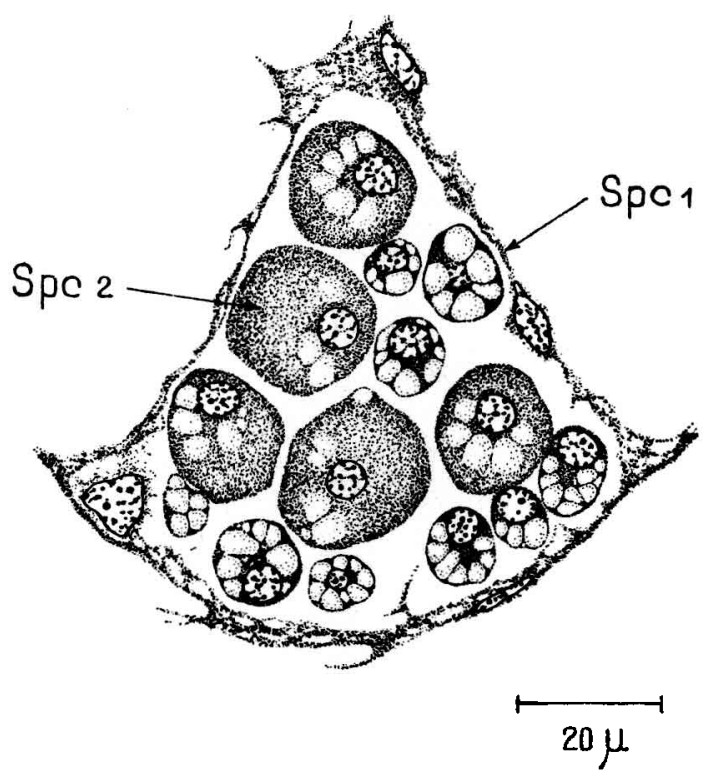

AвB. 21. - Abnorme Spermatogenese : vakuoläre Spermatocyten verschiedener:Grösse Fig. 21. - Spermatogénèse anormale : spermatocytes vacuolaires de différentes_tailles.

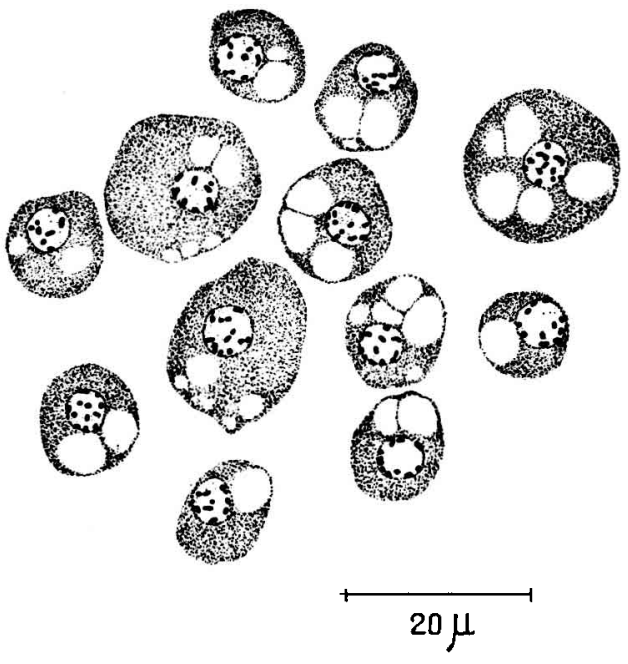

Aвв. 22. - Abnorme Spermatogenese : vormeiotisches Stadium der vakuolären Spermatocyten Fig. 22. - Spermatogénèse anormale : stade pré-meïotique des spermatocytes vacuolaires. 


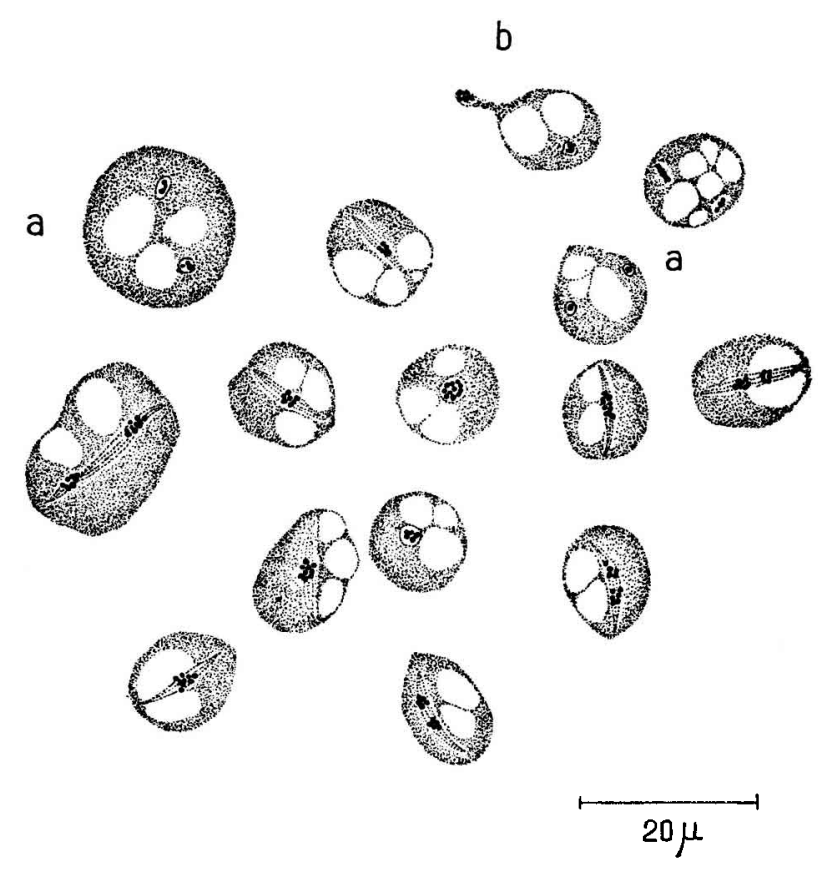

Aв8. 23. - Abnorme Spermatogenese : Reifeteilungen der vakuolären Spermatocyten

FIG. 23. - Spermatogênèse anormale : division de maturation des spermatocytes vacuolaires.

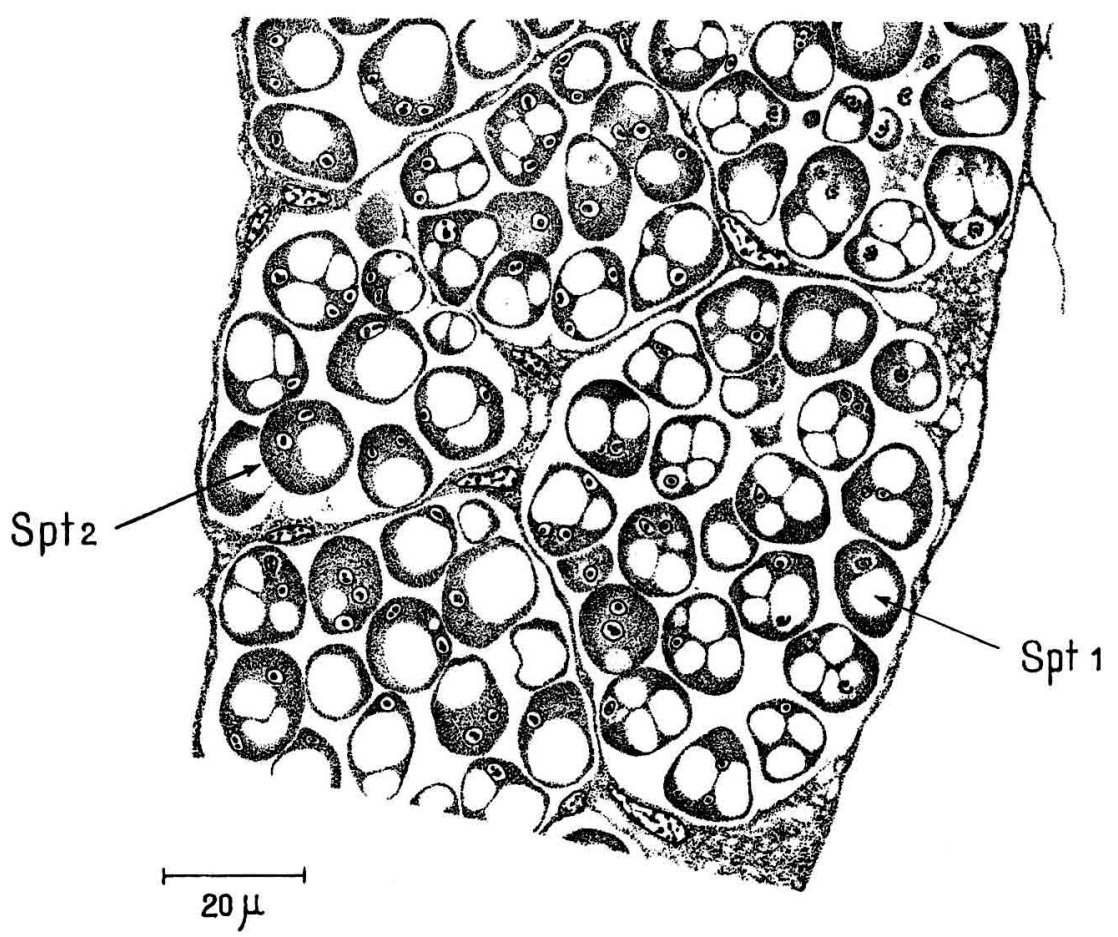

Aв8. 24. - Abnorme Spermatiden

Fig. 24. - Spermatides anormales. 


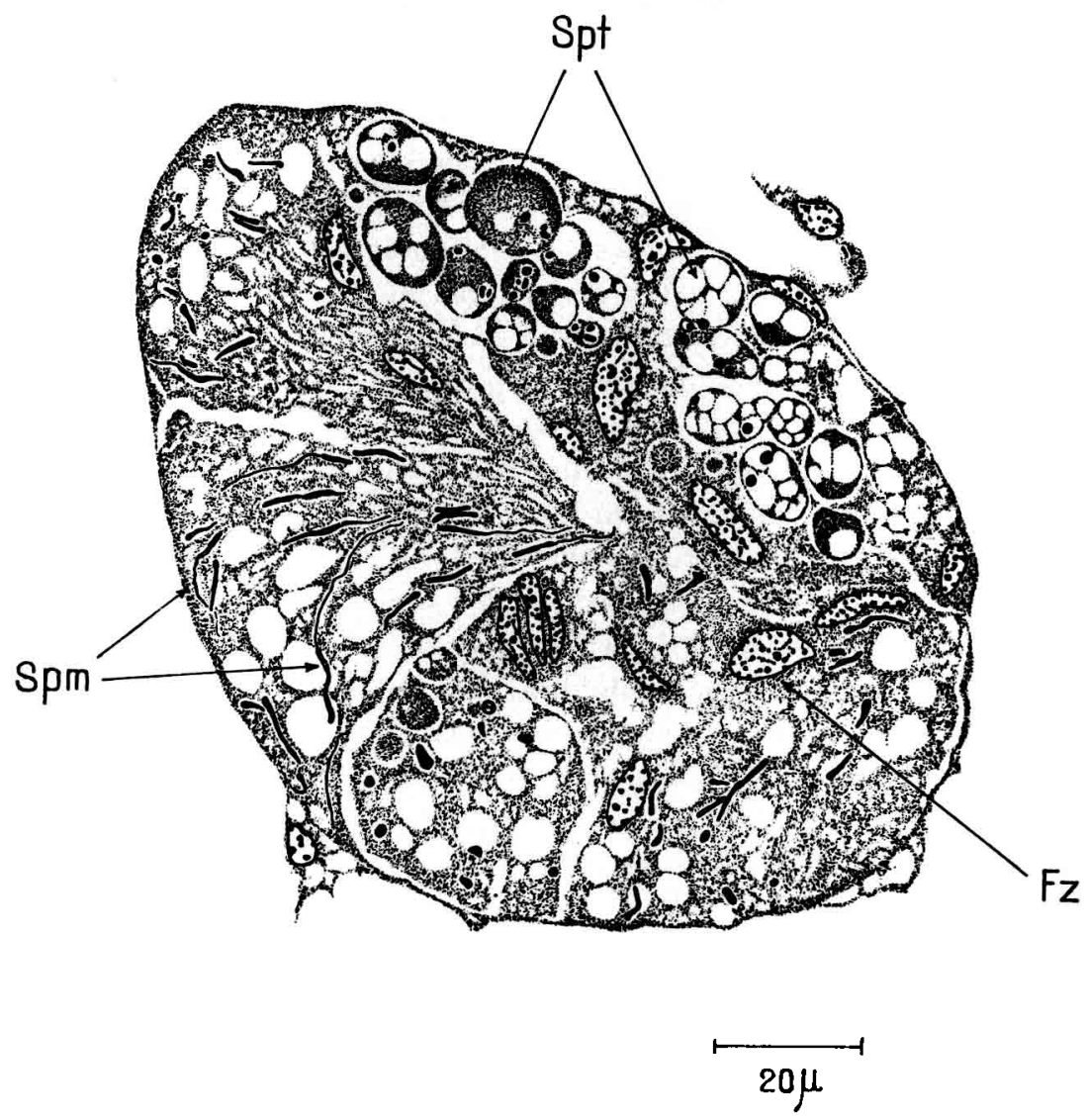

AвB. 25. - Hodenschlauch einer Drohnenpuppe mit abnormer Spermienbildung (Querschnitt)

FIG. 25. - Tube séminifère d'une nymphe de mâle avec spermiogénèse anormale (coupe transversale).

ten, welche mit WEIGERT' schem Eisenhämatoxylin und Eosin oder mit Azokarmin nach Heidenhain-Mallory tingiert werden, ist er nicht zu sehen. Das will aber nicht viel besagen, denn man müsste auch spezifische Mitochondrienfärbungen anwenden, um über die Existenz oder das Fehlen eines solchen Nebenkerns sichern Aufschluss zu erhalten.

Ueber den weitern Fortgang der abnormen Spermatogenese kann ich leider nur sehr wenig mitteilen, da die meisten meiner Versuchstiere vor dem Beginn der Spermiogenese fixiert wurden und sich deshalb für das Studium dieser zweiten Hauptphase der Samenbildung nicht eigneten. Aus diesem Grunde ist nicht bekannt, ob aus den Riesenspermatocyten (Abb. 17, Spc $_{2}$ ) schliesslich irgendwelche Spermien entstehen oder ob sie auf dieser Entwicklungsstufe unverändert stehen bleiben. Dagegen konnte in einigen mikroskopischen Präparaten festgestellt werden, dass sich die abnormen Spermatiden (Abb. 24 und 25, Spt) offenbar noch weiterentwickeln, aber augenscheinlich 
nur zum kleinsten Teil in Spermien (Abb. 25, Spm) verwandeln. Zwischenstadien, wie sie in den Abb. 12 und 13 dargestellt und für die normale Spermatogenese typisch sind, fanden sich allerdings keine. Die spärlichen Samenfäden, welche in einzelnen Hodenschläuchen mehr oder weniger verstreut auftreten, sind nicht gebündelt und zeigen eine interessante morphologische Eigentümlichkeit. Während die stäbchenförmigen Köpfe der ordentlichen Spermien (Abb. 15, Spk) eine Länge von etwa $5.6 \mu$ besitzen, sind diejenigen der abnormen Samenfäden im Mittel $9.5 \mu$ und in einzelnen Fällen sogar bis $13 \mu$ lang. Da der Kopf der fertigen Samenzellen aus dem Spermatidenkern hervorgeht, könnte dieses absonderliche Längenwachstum vielleicht irgendwie mit dem Vorhandensein von zwei und mehr Kernen in den anormalen Spermatiden in Bezeihung stehen. $\mathrm{Ob}$ diese Vermutung berechtig ist, bleibe dahingestellt.

Die vorliegenden Ausführungen bedürfen noch einer kleinen, aber wesentlichen Ergänzung. Bei der histologischen Untersuchung der Drohnenstreckmaden, die entweder geschnürt wurden oder bei welchen im Zeitpunkt der Metamorphose Häutungs - oder Entwicklungs - störungen auftraten, hat sich nämlich gezeigt, dass die Samenbildung bei diesen Tieren nicht immer in sämtlichen Hodenschläuchen regelwidrig verläuft. Wohl gibt es bei ihnen Gonaden, die ausschliesslich abnorme Spermatogenesestadien enthalten. Es kommt aber auch vor, dass dies nur für gewisse, oft herdförmige Hodenbezirke von sehr variabler Grösse zutrifft. Nicht selten beschränkt sich die Anomalie auf die distalen und mittleren Abschnitte der Testiolen. In solchen Fällen findet man dann im proximalen Teil der Hodenschläuche noch normale Samenzellen. Diese recht oft zu beobachtende Lokalisation der regelwidrigen Samenbildung muss bei einem Erklärungsversuch der abnormen Spermatogenese berücksichtigt werden.

\section{B. - Häufigkeit der Spermatogenese-Anomalien}

Die Tabelle 3 gibt Aufschluss über den Verlauf der Metamorphose und Spermatogenese bei 121 Versuchstieren, die im Thermostat teils mit und teils ohne Gespinst aufgezogen wurden.

Wie diese Ưbersicht zeigt, verpuppten sich von den 14 Drohnenlarven, welche den Boden der gläsernen Zuchtschalen mit einem feinen Gespinst belegten, alle normal und wiesen keine Störung der Spermatogenese auf. Diese Befunde bezeugen, dass die künstliche Aufzucht der Larven im Brutschrank beim Vorhandensein eines Gespinstes weder die Metamorphose noch die Samenbildung irgendwie nachteilig beein flusst.

Ein anderes Resultat ergaben indessen die Versuche mit 107 gesunden Drohnenstreckmaden, welche bei gleichen experimentellen Bedingungen, aber ohne Gespinst aufgezogen wurden. Von ihnen entwickelten sich trotz des Fehlens einer Gespinstunterlage immerhin 55, also etwas mehr als die Hälfte ebenfalls zu richtigen Puppen mit normaler Samenbildung. Von den übrigen 
Tabelle 3

\begin{tabular}{|c|c|c|c|c|c|}
\hline \multirow{2}{*}{$\begin{array}{c}\text { Versuchstiere } \\
\text { Animal expérimental }\end{array}$} & \multirow{2}{*}{$\begin{array}{l}\text { Anzahl } \\
\text { Nombre }\end{array}$} & \multicolumn{2}{|c|}{ Metamorphose } & \multicolumn{2}{|c|}{ Spermatogenese } \\
\hline & & $\begin{array}{l}\text { Normal } \\
\text { Normale }\end{array}$ & $\begin{array}{l}\text { Anormal } \\
\text { Anormale }\end{array}$ & $\begin{array}{l}\text { Normal } \\
\text { Normale }\end{array}$ & $\begin{array}{l}\text { Abnorm } \\
\text { Anormale }\end{array}$ \\
\hline $\begin{array}{l}\text { Spinnende Drohnenlarven } \ldots \ldots \ldots \\
\text { Larves de mâles avec cocon. }\end{array}$ & 14 & 14 & $\mathbf{0}$ & 14 & 0 \\
\hline $\begin{array}{l}\text { Drohnen-Streckmaden ohne Ges- } \\
\text { pinst } \ldots \ldots \ldots \ldots \ldots \ldots \ldots \ldots \ldots \ldots \ldots \ldots \\
\text { Larves de mâles allongées sans cocon. }\end{array}$ & 107 & 55 & 52 & 63 & 44 \\
\hline
\end{tabular}

52 Drohnenstreckmaden konnten sich dagegen 37 oder $71 \%$ nicht verwandeln und blieben deshalb auf diesem oder einem mehr oder weniger präpupalen Entwicklungsstadium stehen; bei allen wurde ein typisch abnormer Spermatogeneseverlauf festgestellt. Aus den restlichen 15 Streckmaden gingen schliesslich nur Krüppelpuppen (Abb. 2) hervor und zwar 8 mit normaler und 7 mit regelwidriger Samenbildung. Diese Experimente mit Drohnenstreckmaden bestätigen, dass Häutungsstörungen zur Zeit der Metamorphose tatsächlich häufig einen abnormen Verlauf der Spermatogenese zur Folge haben können.

Wie der Tabelle 4 zu entnehmen ist, gilt das nämliche auch für gewisse Ligaturen, welche im Streckmadenstadium vorgenommen werden.

\begin{tabular}{|c|c|c|c|}
\hline \multirow{2}{*}{$\begin{array}{l}\text { Im Brutschrank bei } \\
35^{\circ} \mathrm{C} \text { aufgezogene } \\
\text { Drohnenstreckmaden } \\
\text { Larve de mâles allongées } \\
\text { élevées à l'étuve à } 35^{\circ} \mathrm{C}\end{array}$} & \multirow{2}{*}{$\begin{array}{l}\text { Anzahl } \\
\text { Nombre }\end{array}$} & \multicolumn{2}{|c|}{ Spermatogenese } \\
\hline & & $\begin{array}{l}\text { Normal } \\
\text { Normale }\end{array}$ & $\begin{array}{l}\text { abnorm } \\
\text { Anormale }\end{array}$ \\
\hline $\begin{array}{l}\text { Mit postcephaler Ligatur } \ldots \ldots \ldots \ldots \ldots \ldots \ldots \ldots \ldots \ldots \ldots \cdots \\
\text { Avec ligature post-céphalique. }\end{array}$ & 12 & 5 & 7 \\
\hline $\begin{array}{l}\text { Mit postthorakaler Ligatur } \ldots \ldots \ldots \ldots \ldots \ldots \ldots \ldots \ldots \ldots \ldots \\
\text { Avec ligature post-thoracique. }\end{array}$ & 7 & 0 & 7 \\
\hline
\end{tabular}

Diese Schnürungsversuche, die ich im Frühjahr und Sommer 1953 im Zusammenhang mit anderen entwicklungsphysiologischen Untersuchungen durchführte (FYG, 1956), ergaben, dass die Samenbildung nach einer Unterbindung hinter dem Kopf in rund $58 \%$ der Fälle und nach postthorakaler Ligatur sogar bei sämtlichen Versuchstieren anormal verlief. Da durch solche 
Eingriffe bestimmte, für das Metamorphosegeschehen sehr wichtige Inkretdrüsen ausgeschaltet werden, liegt die Vermutung nahe, dass die regelwidrige Spermatogenese vielleicht hormonell bedingt sein könnte. Was für einen solchen Zusammenhang spricht, wird im folgenden Abschnitt erörtert.

\section{DISKUSSION}

Die postembryonale Entwicklung und die Metamorphose der Honigbiene werden wie bei anderen Insekten durch die Hormone eines endokrinen Systems ${ }^{1}$ gesteuert, dessen einzelne Glieder untereinander und mit dem Nervensystem in enger Wechselwirkung stehen. $\mathrm{Zu}$ diesen inkretorischen Organen gehören die neurosekretorischen Zellen des Gehirns und der Bauchganglienkette, die Corpora cardiaca, die Corpora allata und während der Postembryogenese die Prothorakaldrüsen.

Bei der Biene liegen die zerebralen, von WEYER (1935) entdeckten neurosekretorischen Zellen (Abb. 26, Nz) in der Pars intercerebralis des Oberschlundganglions (Cgl). Es handelt sich dabei um eine Gruppe von grossen, unipolaren Ganglienzellen, welche im endokrinen System die Rolle eines übergeordneten Zentrums spielen und sich von typischen Neuren nur durch ihre inkretorische Tätigkeit unterscheiden. Ihre teilweise gekreuzten Axone durchziehen das Protocerebrum und verlassen das Gehirn auf der Rückseite als die beiden Nervi corporis cardiaci, um nach kurzem Verlauf in die paarigen Corpora cardiaca (C.c) einzutreten. Weitere, meist isolierte neurosekretorische Zellen finden sich im Unterschlundganglion (Sgl) und in den Nervenknoten des Bauchmarkes (Döнmer, 1958; Biedermans, 1964). Die länglichovalen Corpora cardiaca (C.c) und die kugeligen Corpora allata (C.a) liegen dicht hinter dem Gehirn zu beiden Seiten der Aorta (Ao) und des Oesophagus (Oes) und bilden zusammen das retrocerebrale Hormondrüsensystem. Abgesehen von einer feinen Hülle kann man in den Corpora cardiaca drei verschiedene Bauelemente unterscheiden, nämlich an den Dorsolateralseiten grosse, chromophile Ganglienzellen, mehr zentral und ventral viele kleine Zellen und dazwischen zahlreiche Nervenfasern, welche sich teils gebündelt als Nervi corporis allati bis in die Corpora allata fortsetzen. Die Corpora cardiaca stehen ausserdem über das Hypocerebralganglion (Hy) mit dem die Mundregion und die vorderen Darmabschnitte innervierenden stomatogastrischen Nervensystem ( $\mathrm{Nr}_{\mathrm{r}} \mathrm{Fgl}, \mathrm{Np}$ ) in Verbindung. Die anfänglich flachen, der Aortawand anliegenden Corpora cardiaca werden im letzten Larvenstadiun sichtlich grösser und erreichen in der Puppenzeit ein Volumenmaximum (Lukoschus, 1956). Die Corpora allata (C.a) sind schon in den jüngsten Bienenlarven sehr gut entwickelt und bestehen aus ziemlich grossen, gleichartigen Zellen mit chromatinreichen Kernen. Ein Lumen fehlt diesen Inkretdrüsen. In jedem Corpus allatum ist lediglich ein dorsomedialer Hilus als Nerveneintrittstelle vorhanden. Das Volumen der Corpora allata nimmt in der Larvenzeit sowohl bei der Arbeitsbiene als auch besonders bei der Königin ständig zu und erreicht im 5 . Larvenstadium ein Maximum. In der Streckmade werden dann die Drüsen in beiden Kasten wieder kleiner. Nach der Metamorphose erfolgt bei der Königin im Puppenstadium neuerdings ein starker Volumenanstieg, welcher bei der Arbeitsbiene unterbleibt. LukoscHus (1956) vermutet, dass dieses unterschiedliche Verhalten der Corpora allata mit der Ausbildung der Eierstöcke zusammenhängt, denn zu dieser Zeit beginnen sich die Ovarien der Bienenkönigin beträchtlich zu entwickeln, während bei der Arbeiterin eine Rückbildung der Ovariolen stattfindet. Die Prothorakaldrüsen (Abb. 26 und 27, Pdr) befinden sich im vordersten Rumpfsegment, aus welchem der Prothorax hervorgeht. Diese Hormondrüsen, die vom Unterschlundganglion oder ersten Thorakalganglion (Thg ${ }_{1}$ ) innerviert werden, setzen sich aus losen und öfters verzweigten Zellsträngen und einzelnen Zellgruppen zusammen. Ihre Hauptmasse

1. Literatur : Nabert, 1913; Nelson, 1915, 1924; Hanström, 1942; Cazal, 1948; Pflugfelder,

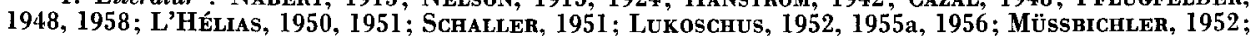
Thomson, 1954; Hanan, 1955; Formigoni, 1956; Snodgrass, 1956; Döhmer, 1958; Fyg, 1963; BiedermanN, 1964; Gast, 1967; Hüsing, 1968; Chavvin, 1968; Herrmann, 1969; Lamotke, 1969. 


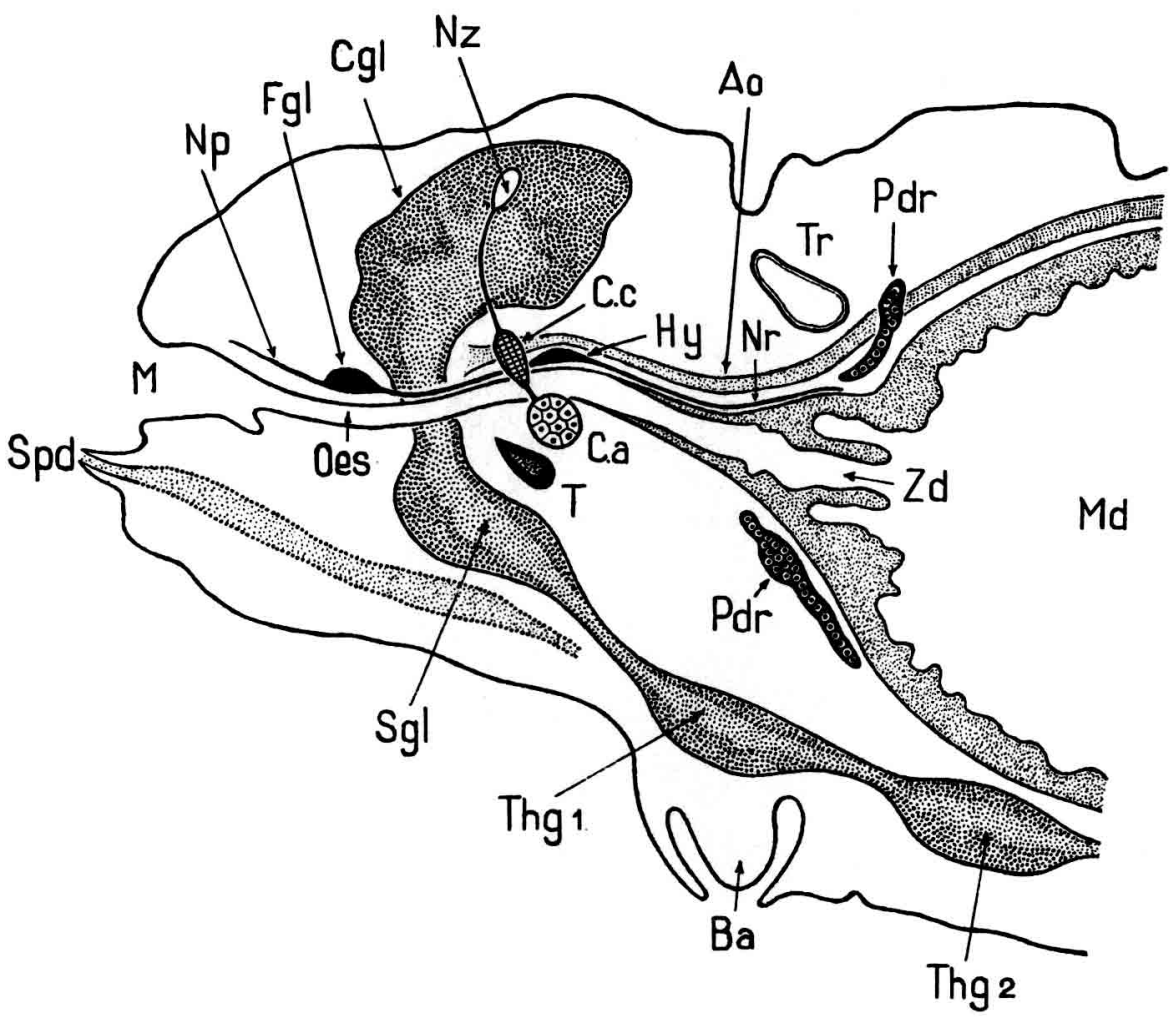

Aв8. 26. - Halbschematischer Längsschnitt durch die Kopf- und Prothoraxregion einer Bienenlarve FIG. 26. - Coupe longitudinale semi-schêmatique à travers la tête et la région pro-thoracique d'une larve d'abeille.

liegt unter und beidseitig der Einmündung des Vorderdarmes (Oes, Zd) in den Mitteldarm (Md). Von hier ziehen mehrere bilaterale Zellketten in oraler und dorsaler Richtung und endigen teils in der Nähe der Corpora allata, teils an den vordersten Brusttracheen. Die Prothorakaldrüsen der Honigbiene wachsen in den älteren Larven, insbesondere bei den Königinnen- und Drohnenmaden stark heran, beginnen aber wie bei anderen Insekten bereits im Puppenstadium zu atrophieren und versehwinden schliesslich ganz, weshalb sie den Imagines fehlen.

In Anbetracht der reichlichen Literatur über die Funktionen des endokrinen Systems während der Postembryogenese und Metamorphose der Insekten ${ }^{1}$ genügen im Rahmen der vorliegenden Abhandlung einige summarische Hinweise, welche im wesentlichen auch für die Honigbiene gelten (Lukoschus, 1955, 1955a, 1956). Die intercerebralen neurosekretorischen Zellen produzieren adenotrope Wirkstoffe, welche über die Verbindungsnerven in die als Durchgangs-, Speicher- und Vermittlungsstelle dienenden Corpora cardiaca und von hier zum Teil bis in die Corpora allata gelangen. Ein

1. Literatur : Bodenstein, 1953a, 1953b; SCHARRER, 1952, 1953; WigglesWorTH, 1954, 1965; GensCH, 1956, 1961, 1964; Karlson, 1956, 1959; Novak, 1956, 1959; Pflugfelder, 1958; Gilbert, 1964; KühN, 1965; WeBER, 1966; JoLY, 1968. 


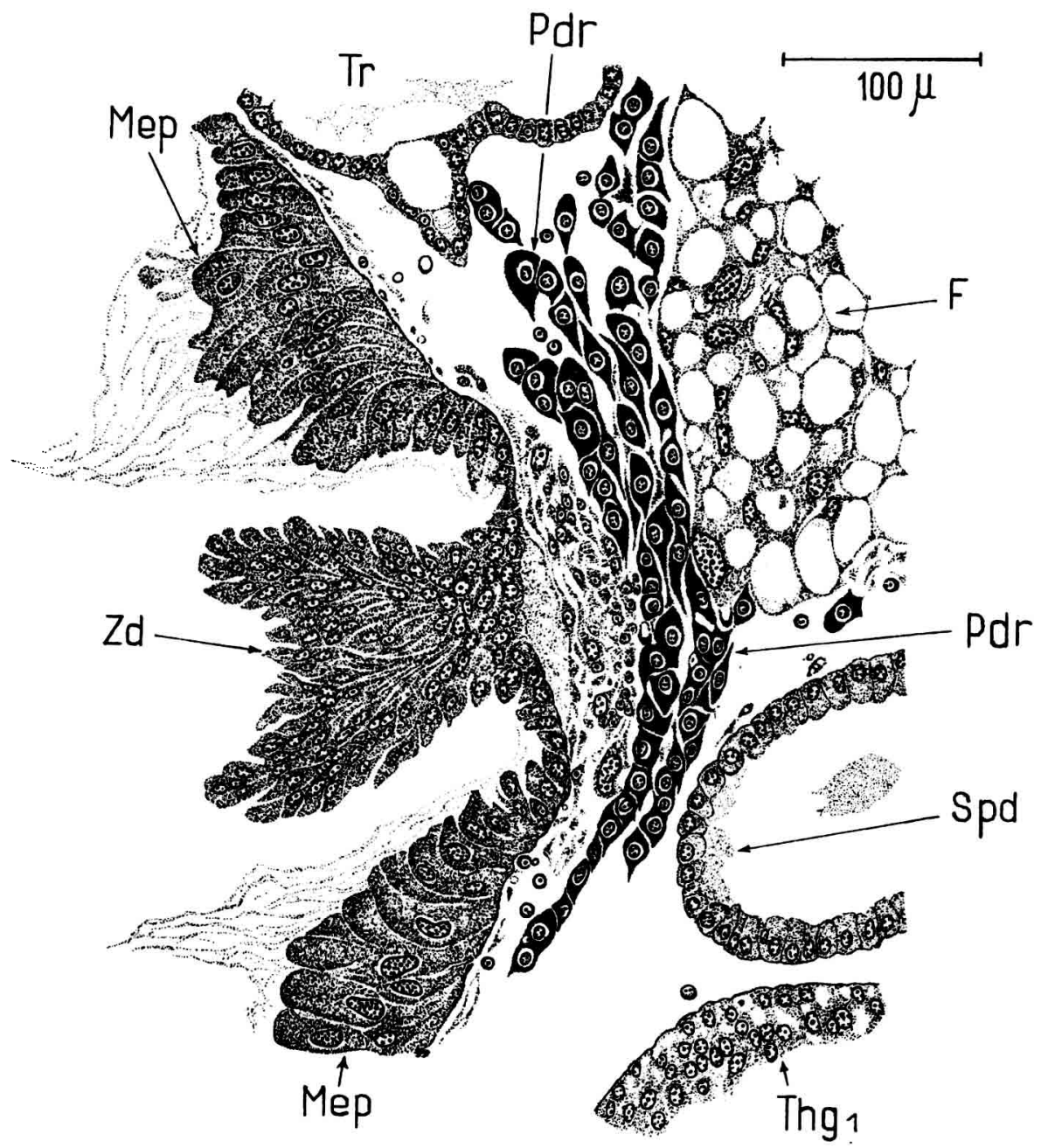

Aвв. 27. - Prothorakaldrüse einer älteren Drohnenlarve (Sagittalschnitt)

Fig. 27. - Glande pro-thoracique d'une larve de mâle âgée (coupe sagittale).

solcher Inkretstrom wurde von verschiedenen Autoren mit der ParaldehydFuchsinfärbung nach GABE (1953) oder mit GoMori's Chromalaunhämatoxylin-Phloxin (1941) bei einer ganzen Reihe von Insekten, so auch bei der adulten Honigbiene ${ }^{1}$ nachgewiesen. Die Neurosekrete des Gehirns aktivieren die Corpora allata sowie die Prothorakaldrüsen und veranlassen sie zur Ausschüttung ihrer eigenen Hormone, welche die durch schrittweise Häutungen gekennzeichnete postembryonale Entwicklung steuern. Die Corpora allata liefern im

1. Literatur : Thomsen, 1954; Formigoni, 1956; Döhmen, 1958; Biedermanv, 1964; Gast, 1967; HenhmanN, 1969. 
Madenstadium ein Larval- oder Juvenilhormon, das für die Erhaltung des larvalen Zustandes sorgt und die Verpuppung verhindert. Der Wirkstoff der Prothorakaldrüsen (Ecdyson) löst die einzelnen, mit dem Wachstum in Beziehung stehenden Häutungen aus und führt ohne Larvalhormon die Verwandlung und imaginale Entwicklung herbei. Die Metamorphose kommt bei den holometabolen Insekten dadurch zustande, dass die Corpora allata kurz vor Beendigung des letzten Larvenstadiums die Sekretion von Juvenilhormon weitgehend oder ganz einstellen, so dass dann das antagonistische Prothorakaldrüsenhormon im Blut überwiegt und die Verwandlung bewirkt.

Unter diesen Umständen ist es verständlich, dass während der Postembryogenese jeder künstliche Eingriff in das innersekretorische System die natürlichen hormonellen Verhältnisse in dem sich entwickelnden Organismus mehr oder weniger tiefgreifend beein flusst und dementsprechende Folgen hat (Novák, 1956). Das bestätigen auch die Schnürungsversuche, welche von l'Hélias (1951), Schaller (1951a, 1952), Lukoschus (1955a) und Fyg (1956, 1962) an Bienenlarven und Bienenpuppen ausgeführt wurden. Im Larvenstadium verhindert eine rechtzeitige postcephale Schnürung hinter der Ligatur die normale Wirksamkeit der adenotropen Neurosekrete des Oberschlundganglions sowie der Inkrete der Corpora cardiaca und Corpora allata. Im Rumpf verbleiben in diesem Fall von den bis jetzt sicher bekannten Hormonspendern nur die Prothorakaldrüsen. Durch eine postthorakale Unterbindung werden auch diese inkretorischen Organe vom Hinterkörper getrennt. Wie zahlreiche Versuche ergaben, hängt der erzielte Effekt hauptsächlich davon ab, in welchem Zeitpunkt der Postembryogenese die operativen Eingriffe vorgenommen werden. Schnürt man Bienenlarven in den ersten $6-12$ Stunden nach Beginn des Spinnens hinter dem Kopf, so entwickelt sich der Rumpf in der Regel nicht weiter. Bei späteren postcephalen Ligaturen entstehen sogenannte Zwischenformen, d.h. Tiere mit larvalem Kopf und einem Hinterkörper, welcher mehr oder minder weitgehend pupal-imaginal differenziert ist. Entscheidend für den Grad dieser Differenzierung ist das jeweilige Mengenverhältnis der Larval- und Prothorakaldrüsenhormone im Rumpf. Ähnliche Zwischenformen gehen aus Bienenlarven und Streckmaden nach Thoraxschnürungen hervor, wobei sich - vor allem nach frühzeitiger Unterbindung - die Weiterentwicklung vorwiegend im Vorderkörper geltend macht.

Im Zusammenhang mit den vorliegenden Untersuchungen über die abnorme Spermatogenese ist die Feststellung von Schaller besonders beachtenswert, dass sich bei den geschnürten Arbeiterinnenlarven die zeitlich regelwidrigen und hormonbedingten pupal-imaginalen Differenzierungen nicht auf das Integument beschränken, sondern ausserdem an gewissen innern Organen wie Muskulatur und Darmtrakt in Erscheinung treten. Im weiteren konnte Lukoscrus experimentell nachweisen, dass bei Metamorphosestadien der Honigbiene sowohl die Ausbildung der epidermalen Kleinorgane wie Haare und Borsten als auch die Entwicklung und das Grössenwachstum der Duft-, 
Futtersaft- und Wachsdrüsen von Hormonen abhängig sind. Das könnte möglicherweise für die männlichen Gonaden ebenfalls zutreffen. Dann wäre es immerhin denkbar, dass die abnorme Samenbildung in den Hoden der ligierten Drohnenstreckmaden (Tab. IV) irgendwie mit der Veränderung der hormonellen Verhältnisse in Beziehung steht. Dafür scheinen mir vor allem die Spermatogenesebefunde bei den 7 postthorakal-geschnürten Streckmaden zu sprechen, von denen keine einzige eine normale Samenbildung aufwies. Die unterschiedlichen Ergebnisse nach postcephaler Ligatur sind vermutlich darauf zurückzuführen, dass die 12 so behandelten Versuchstiere im Augenblick des Eingriffes nicht alle gleichalterig waren und deshalb teils vor, teils nach einer kritischen Periode der Hormonaktivität unterbunden wurden. Ob diese Deutung richtig ist, müsste allerdings an einem grösseren Untersuchungsmaterial erst noch ergründet werden, wobei auch dem jeweiligen $\mathrm{Zu}$ stand der endokrinen Drüsen gebührende Beachtung zu schenken wäre.

Die identischen Anomalien in der Samenbildung, welche bei Drohnenstreckmaden vielfach nach Metamorphose-Häutungsstörungen auftreten (Tab. III), lassen sich vielleicht in analoger Weise erklären. Bei den mannigfachen Wechselbeziehungen zwischen den endokrinen Organen und dem Nervensystem ist es nicht ausgeschlossen, dass exogene, von den larvalen Hautsinnesorganen (Luкоschus, 1955; Fyg, 1966) perzipierte Reize dem Gehirn und von da den Inkretdrüsen zugeleitet werden. Ein Ausfall solcher Reize, wie er beim Fehlen des Larvengespinstes sehr wahrscheinlich eintritt, könnte wohl eine Änderung der hormonellen Verhältnisse im verwandlungsbereiten Organismus herbeiführen und so die Spermatogenese beein flussen. Die bereits erwähnte und scheinbar widersprüchliche Beobachtung, dass sich bei meinen Versuchen ziemlich viele Drohnenstreckmaden auch ohne Gespinst normal verpuppten und keine abnorme Samenbildung zeigten, beruht möglicherweise auf einer unterschiedlichen Sensibilität der verschiedenalterigen Versuchstiere; sie könnte davon abhängig sein, in welchem Zeitpunkt der Entwicklung die Gespinstunterlage ausgeschaltet wird.

Ganz abgesehen davon, dass über die Art der hormonellen Störungen, welche in den vorliegenden Fällen infolge der Schnürungen und Häutungsanomalien offenbar auftreten, leider nichts ausgesagt werden kann, genügen meine experimentellen Ergebnisse natürlich noch keineswegs, um die Abhängigkeit der Spermatogenese der Honigbiene von der Tätigkeit der inkretorischen Organe zu beweisen. Es dürfte sich aber gewiss lohnen, das Problem an diesem so leicht zu beschaffenden und sehr geeigneten Objekt gründlicher zu studieren, da schon lange bekannt ist, dass bei verschiedenen Insekten Hormone für die Reifung der Gonaden und Geschlechtszellen erforderlich oder mindestens von grosser Bedeutung sind ${ }^{1}$. Was die Biene anbetrifft, gibt es

1. Literatur : Wigglesworth, 1954, 1964; DoANe, 1963; HighNam, 1964; Weber, 1966; EngelmanN, 1968. 
ebenfalls einige Anhaltspunkte, welche für eine Abhängigkeit der Eireifung von Wirkstoffen der zerebralen neurosekretorischen Zellen oder der Corpora allata sprechen 1, obwohl HrdÝ et Slama (1964) gestützt auf ihre Allatektomie-Versuche an adulten Bienenköniginnen das letztere verneinen. Wenn hier die Vermutung geäussert wird, dass bei der Honigbiene möglicherweise auch die Spermatogenese von Hormonen beein flusst wird, so schliesst das selbstverständlich nicht aus, bei künftigen Untersuchungen über die abnorme Samenbildung in den Hoden der Drohne noch andere als hormonelle Ursachen in Erwägung zu ziehen.

Eingegangen im April 1973.

Reçu pour publication en avril 1973.

\section{RÉSUMÉ}

Des recherches antérieures de VELICH $(1930)$ et de Fyg $(1956,1957)$ ont montré que chez l'abeille le cocon joue un rôle important dans le déroulement normal de la mue nymphale. Lorsque des larves d'ouvrières ou de mâles prêtes à se nymphoser sont élevées à l'étuve dans des conditions normales mais sans cocon, on constate que la mue nymphale, ou bien n'a pas lieu du tout, ou bien se déroule dans des conditions aberrantes de telle sorte qu'on n'obtient que des abeilles plus ou moins déformées et non viables. Le cocon exerce apparemment sur le corps de la larve une excitation qui est indispensable au déclenchement de la mue nymphale; cette excitation est perçue par les nombreux organes sensoriels tactiles et conduite par le système nerveux central jusqu'aux glandes endocrines. Une étude histologique de larves allongées de mâles qui, privées de leur cocon, ne s'étaient pas nymphosées du tout ou bien ne s'étaient nymphosées que de façon incomplète, a permis de constater que la spermatogénèse est, dans ce cas, totalement anormale. On trouve dans les testicules des spermatocytes géants et des spermatides aberrantes qui ne se transforment en spermies que dans une très faible proportion. Les mêmes anomalies de la formation des spermatozoïdes se produisent d'ailleurs lorsque les processus incrétoires normaux sont perturbés chez les grosses larves ou chez les pré-nymphes à un stade précoce par une ligature post-céphalique ou post-thoracique. Du fait que par de telles ligatures on sépare des glandes à sécrétion interne bien déterminées d'avec l'abdomen qui contient les gonades, on peut supposer que les anomalies de la spermatogénèse qui se produisent sous l'influence des perturbations de la métamorphose nymphale ou de ligatures sont finalement conditionnées par les hormones.

Dans le présent travail, après la présentation introductive des expériences réalisées on décrit tout d'abord à partir de dessins originaux la spermatogénèse normale (fig. 3-15) puis la spermatogénèse anormale (fig. 16-25). Pour terminer, après quelques courtes explications sur le système endocrine de l'abeille et ses fonctions, on expose les arguments qui plaident en faveur d'une relation présumée entre la spermatogénèse et l'activité des organes incrétoires.

\section{LITERATUR}

Altmann G., 1952, Die Lokalisation der Sexualwirkstoffe bei der Honigbiene. Z. Bienenforsch. 1 : $124-128$.

1. Literatur : AltmanN, 1952; Lukoschus, 1956; Lüschen et Waxker, 1963; BiedermanN, 1964; Gast, 1967; Herrmann, 1969. 
Arnhart L., 1919, Das Puppenhäuschen der Honigbiene. Z. angew. Entomol. 5 : 231-251.

Biedermanv M., 1964, Neurosekretion bei Arbeiterinnen und Königinnen von Apis mellifica L. unter natürlichen und experimentellen Bedingungen. Z. wiss. Zool. 170 : 256-308.

Bissop G. H., 1920, Fertilization in the honey-bee. I The males sexual organs : Their histological structure and physiological functioning. J. exp. Zool. 31 : 225-265.

Bodenstein D., 1953a, Endocrine control of metamorphosis with special reference to Holometabola. Trans. 9th int. Congr. Entomol. 19512 : 58-62.

Bodenstein D., 1953b, The role of hormones in molting and metamorphosis. in : Roeder, K. D. : Insect Physiology. John Wiley et Sons, Inc. New York (1953).

Buchner P., 1915, Praktikum der Zellenlehre. Verlag Gebr. Borntraeger, Berlin.

V. Buttel-Reepen H., 1907, Ueber Kokonspinnen der Bienen. Bienenwirtsch. Centralbl. 43 : 196.

Cazal P., 1948, Les glandes endocrines rétrocérébrales des insectes. Bull. Biol. France-Belge, Suppl. 32.

Chauvin R., 1968, Développement et croissance. II. La mue, la cuticule et les formations cuticulaires chez l'abeille. Traité de Biologie de l'Abeille. Masson et Cie. Paris, 1 : 100-128.

Church N. St., 1955, Hormones and termination and reinduction of diapause in Cephus cinctus Nort. (Hymenoptera) Canad. J. Zool. 33 : 339-369.

Doane W. W., 1963, Endocrine control of reproduction. in : Brookes, V. J. : Insect Physiology. Oregon State Univ. Press, Corvallis, Oregon 65-88.

Döhmer I, 1958, Das neurosekretorische System der Honigbiene, insbesondere der Arbeiterinnen verschiedenen Alters. Diss. Univ. Berlin, 1-39.

Doncaster L., 1906/07, Spermatogenesis in the Hive Bee (Apis mell. L.). Anat. Anz. 29 : $490-491 ; 31: 168-169$.

Engelmann F., 1968, Endocrine control of reproduction in insects. Ann. Rev. Entomol. $13: 1-26$.

Fonmiconi A., 1956, Neurosécrétion et organes endocrines chez Apis mellifica L. Ann. Sci. Nat. Ser. 11, Zool. et Biol. anim. 18 : 283-291.

Fyg W., 1956, Experimentelle Untersuchungen über die Entwicklung der Honigbiene. Mitt. Schweiz. Entomol. Ges. 29 : 404-416.

FYG W., 1956a, Über die Notwendigkeit des Larvengespinstes für die normale Puppenentwicklung der Honigbiene. Mitt. Schweiz. Entomol. Ges. 29 : 317.

Fyc W., 1957, Über die Phaenokopierung einer erblich bedingten Missbildung der Honigbiene (Apis mellifica L.). Insectes sociaux $4: 327-334$.

Fyc W., 1958, Über die normale und abnorme Entwicklung der Honigbiene. Schweiz. Bienenztg. NF 81 : 147-154, 387-389.

FyG W., 1961, Eine einfache Methode zur Gewinnung von Exuvialflüssigkeit bei der Honigbiene (Apis mellifica L.). Experientia $17: 474$.

Fyg W., 1962, Beitrag zur Pathologie der Sackbrut. Z. Bienenforsch. 6 : 93-103.

Fyg W., 1963, Anomalien und Krankheiten der Bienenkönigin. Bull. apic. 6 : 7-151.

FyG W., 1966, Beitrag zur Kenntnis der larvalen Hautsinnesorgane der Honigbiene (Apis mellifica L.). Mitt. Schweiz. Entomol. Ges. 38 : 183-192.

GABE M. 1953, Sur quelques applications de la coloration par la Fuchsine-Paraldéhyde. Bull. Micr. appl. Paris 3 : 153-162.

GAST R., 1967, Untersuchungen über den Einfluss der Königinnensubstanz auf die Entwicklung der endokrinen Drüsen bei der Arbeiterin der Honigbiene (Apis mellifica). Insectes sociaux 14: 1-12.

Gersce M., 1956, Das Hormonsystem der Insekten auf Grund neuerer Forschungsergebnisse. Bericht 100-Jahrfeier Dtsch. Entomol. Ges. 146-169.

Gersce M, 1961, Insect metamorphosis and the activation hormone. Amer. Zoologist 1 : 53-57.

Gersch M, 1964, Vergleichende Endokrinologie der wirbellosen Tiere. Akad. Verlagsges. Leipzig. 
Gersch M, 1968, Neuroendokrinologie der Insekten. Sitzungsber. sächs. Akad. Wiss. Leipzig. Math.-nat. K1. 108.

Giglio-Tos E., 1905, Della partenogenesi e della spermatogenesi nell'ape. Anat. Anz. 26 : 369-373.

Gilbert L., 1964, Physiology of growth and development : endocrine aspects. In : Rockstein, M. : The Physiology of Insecta. Acad. Press, New York et London, 1 : 149-255.

GoмоrI G., 1941, Observations with differential stains on Human islets of Langerhans. Amer. J. Path. $17: 395-406$.

Gontarski H., 1957, Die Orientierung der Larve von Apis mellifica in der geschlossenen Zelle. Z. Bienenforsch. 3 : 216-220.

Hachivohe Y. et ONishi N., 1952, Meiosis in the drone honeybee (Apis mellifica L.). Bull. Nat. Inst. Sci. Yahagi-Cho, Chiba-shi, Japan Ser. G. 3 : 83-87.

Hanan B., 1955, Studies on the retrocerebral complex in the honeybee. Part. I : Anatomy and histology. Ann. Entomol. Soc. Amer. 48 : 315-320.

Hanström B., 1942, Die Corpora cardiaca und Corpora allata der Insekten. Biol. Gen. 15 : $485-531$.

Herrmanv H., 1969, Die neurohormonale Kontrolle der Paarungs flüge und der Eilegetätigkeit bei der Bienenkönigin. Z. Bienenforsch. 9 : 509-544.

Highnam K. C., 1964, Endocrine relationships in insect reproduction. Roy. Entomol. Soc. Symp. No. $2: 26-42$.

Hrdý J. et Slama K., 1963, Der Einfluss der Allatektomie auf die Eiablage der Bienenköniginnen. Vorträge XIX. int. Bienenzüchterkongress in Prag, 1 : 203-205.

Hưssivg J. O., 1968, Système nerveux central. In : Chauvin, R. : Traité de Biologie de l'Abeille. Masson et Cie. Paris, 2 : 45-48.

JAY S. C., 1961, The longitudinal orientation of larval honey bees (Apis mellifica L.) within cells. Anim. Behaviour 9 : 230-231.

JaY S. C. 1962, Prepupal and pupal ecdysis of the Honeybee. J. apic. Res. 1 : 14-18.

JAY S. C. 1963, The development of honey-bees in their cells. J. apic. Res. 2 : 117-134.

Jegen G., 1919, Zur Spermatogenese bei Apis mellifica. Verh. Schweiz. Naturforsch. Ges. 119.

JoLy P., 1968, Endocrinologie des Insectes. Masson et Cie. Paris.

Jung-Hoffmann I, 1968, Développement des larves. In : Chauvin, R. : Traité de Biologie de l'Abeille. Masson et Cie, Paris 1 : 69-99.

Karlson P., 1956, Chemische Untersuchungen über die Metamorphosehormone der Insekten. Ann. Sci. Nat., Zool. et Biol. anim. 18 : 125-137.

Karlson P., 1959, Zur Chemie und Wirkungsweise der Insektenhormone. IV. int. Kongr. Biochem. 12 : 35-4.7.

KüнN A., 1965, Vorlesungen über Entwicklungsphysiologie. 2. Aufl. Springer Verlag, Berlin.

Kurennor N. M., 1953, When are drones sexually mature? Ptschelowodstwo 11 : 28-32. Engl. Uebersetzung Bee Res. Ass. London 1954.

Lamotke G., 1969, Neurosekretion im Gehirn der Drohnen. Z. Bienenforsch. 9 : 434-451.

Leuenberger F., 1954, Die Biene. 3. Aufl. Verlag H. R. Sauerländer et Co. Aarau.

L'HÉltas C., 1950, Étude des glandes endocrines postcérébrales de la larve d'Apis mellifica. Bull. Soc. Zool. France 75 : 70-74.

L'HÉlras C., 1951, Expériences de ligatures chez la larve d'Apis mellifica. C. R. Soc. Biol. Paris $145: 233-234$.

Lotmar R., 1945, Die Metamorphose des Bienendarmes (Apis mellifica) Beihefte z. Schweiz. Bienenztg. 1 : 443-506.

Luкоschus F., 1952, Über die Prothoraxdrüse der Honigbiene (Apis mellifica L.). Naturwissenschaften $39: 116$.

Lukoschus F., 1955, Über Hautsinnesorgane der Bienenlarve. Z. Bienenforsch. 3 : 85-87.

Luкоschus F., 1955a, Untersuchungen zur Metamorphose der Honigbiene (Apis mellifica L.). Insectes sociaux 2 : 147-162. 
Lukoschus F., 1955b, Die Bedeutung des innersekretorischen Systems für die Ausbildung epidermaler Kastenmerkmale bei der Honigbiene (Apis mellifica L.). Insectes sociaux 2 : 221-236.

Lukoschus F., 1956, Untersuchungen zur Entwicklung der Kastenmerkmale bei der Honigbiene (Apis mellifica L.). Z. Morph. Oekol. Tiere 45 : 157-197.

Lüscher M. et Walker I, 1963, Zur Frage der Wirkungsweise der Königinnenpheromone bei der Honigbiene. Rev. suisse Zool. 70 : 304-311.

Mark, E. L. et Copeland M., 1907, Some stages in the spermatogenesis of the honeybee. Proc. Amer. Acad. Arts and Sci. 42 : 103-111.

Meves F., 1900, Über den von La Valette St. George entdeckten Nebenkern (Mitochondrienkörper) der Samenzellen. Arch. mikr. Anat. 56.

Meves F., 1903, Über a Richtungskörperbildung 》 im Hoden von Hymenopteren. Anat. Anz. 24.

Meves F., 1907, Die Spermatocytenteilungen der Honigbiene (Apis mellifica L.) nebst Bemerkungen über die Chromosomenreduktion. Arch. mikr. Anat. 70 : 414-491.

Meves F. et Duesberg J., 1908, Spermatocytenteilungen bei der Hornisse (Vespa crabro L.). Arch. mikr. Anat. 71.

Mındт B., 1962, Untersuchungen über das Leben der Drohnen, insbesondere Ernährung und Geschlechtsreife. Z. Bienenforsch. $6:$ 9-33.

Mongan Th. H. 1921, Die stoffliche Grundlage der Vererbung. Verlag Gebr. Borntraeger, Berlin.

Müssbichler A., 1952, Die Bedeutung äusserer Einflüsse und der Corpora allata bei der Afterweiselentstehung von Apis mellifica. Z. vergl. Physiol. 34 : 207-221.

NABert A., 1913, Die Corpora allata der Ineskten. Z. wiss. Zool. 104 : 181-358.

Nachtsheim H., 1913, Cytologische Studien über die Geschlechtsbestimmung bei der Honigbiene (Apis mell. L.). Arch. Zellforsch. 11 : 169-24l.

Nelson J. A., 1915, The Embryology of the Honey Bee. Princeton Univ. Press.

Nelson J. A., 1924, Morphology of the honeybee larva. J. Agr. Res. 28 : 1167-1213.

Novák V. J., 1956, Versuch einer zusammenfassenden Darstellung der postembryonalen Entwicklung der Insekten. Beitr. Entomol. 6 : 205, 464-493.

Novák V. J., 1959, Insektenhormone. Verlag Tschechoslowak. Akad. Wiss. Prag.

Pflugfelder O., 1948, Volumetrische Untersuchungen an den Corpora allata der Honigbiene (Apis mellifica L.). Biol. Zbl. 67 : 223-241.

Pflugfelden O, 1958,. Entwicklungsphysiologie der Insekten. 2. Aufl. Akad. Verlagsges. Geest et Portig, Leipzig.

Prell H., 1924, Der Kokon der Honigbiene. Erlanger Jb. Bienenkunde 2 : 176-189.

Risler H., 1954, Die somatische Polyploidie in der Entwicklung der Honigbiene (Apis mellifica L.) und die Wiederherstellung der Diploidie bei den Drohnen. Z. Zellforsch et mikr. Anat. $41: 1-78$.

Roeder K. D., 1953, Insect Physiology. John Wiley et Sons, Inc. New York.

Rutrner F., 1966, Fortp flanzungsorgane der Drohnen und Bienenköniginnen. Apimondia Symp. Dol, 22-45.

Rutrner F., 1968, Sexualité et reproduction. In : Chauvin, R. : Traité de Biologie d'Abeille. Masson et Cie. Paris 1 : 145-185.

Rutrner F., 1968a, Génétique. In : Chauvin, R. : Traité de Biologie d'Abeille. Masson et Cie. Paris 4: 198-236.

Sanderson A. R. et Hall D. W., 1948, The cytology of the honey bee (Apis mell. L.). Nature 162 : 34-35.

Sanderson A. R. et Hall D. W., 1951, Sex in the honey-bee. Endeavour 10 : 33-39.

SAnderson A. R. et Halc D. W., 1951a, Sex determination in the honey bee. Evolution 5 : 414-415.

Schaller F., 1951, Étude morphologique du complexe endocrine rétro-cérébral de la larve d'abeille (Apis mellifica L.). C. R. Soc. Biol. 145 : 1097-1200. 
SChaller F., 1951 a, Réalisation des caractères de caste au cours de développements perturbés chez l'abeille (Apis mellifica L.). C. R. Soc. Biol. Paris 145 : 1351.

Schaller F., 1952, Effets d'une ligature postcéphalique sur le développement des larves âgées d'Apis mell. L. Bull. Soc. Zool. France 77 : 195-204.

Scharrer B., 1952, Hormones in insects. In : The Action of Hormones in Plants and Invertebrates. Acad. Press, Inc. New York. 125-169.

Scharrer B., 1953, Comparative Physiology of Invertebrate. Endocrines. Ann. Rev. Physiol. 15 : $457-472$.

Snodgrass R. E., 1956, Anatomy of the Honey Bee. Comstock Publ. Assoc. New York.

Thomsen M., 1954, Neurosecretion in some Hymenoptera. Danske Vidensk. Selskab. Biol. Skr. 7.

Velich A. V., 1930, Entwicklungsmechanische Studien an Bienenlarven. Z. wiss. Zool. 136 : 210-222.

Weber H., 1966, Grundriss der Insektenkunde. 4. Auf. Gustav Fischer Verlag, Stuttgart.

Weyer F., 1935, Üeber drüsenartige Nervenzellen im Gehirn der Honigbiene (Apis mellifica L.). Zool. Anz. 112 : 137-141.

White M. J. D., 1957, Cytogenetics and systematic entomology. Ann. Rev. Entomol. 2 : $71-90$.

Wigglesworti V. B., 1954, The Physiology of Insect Metamorphosis. Cambridge, Univ. Press.

Wigglesworth V. B., 1965, The Principles of Insect Physiology. 6th. ed. Methuen et Co. Ltd. London.

Wigglesworth V. B., 1964, The Hormonal Regulation of Growth and Reproduction in Insects. Advan. Insect Physiol. 2 : 247-344.

Wolf B. E., 1960, Eine Nachuntersuchung zur Cytologie der Honigbiene. Zool. Beitr. 5 : 373-391.

Zander E., 1916, Die postembryonale Entwicklung des Geschlechtsapparates der Drohne (Apis mellifica L.). Z. angew. Entomol, 3 : 7-20. 